\author{
UNIVERSIDADE DE SÃO PAULO \\ FACULDADE DE MEDICINA DE RIBEIRÃO PRETO \\ PROGRAMA DE PÓS-GRADUAÇÃO EM SAÚDE PÚBLICA
}

FERNANDO BARBOSA PEIXOTO

\title{
Ingestão de nutrientes e sua relação com a Síndrome da Fragilidade em idosos de uma unidade de Saúde da Família de Ribeirão Preto, São Paulo.
}

Ribeirão Preto

2019 



\section{FERNANDO BARBOSA PEIXOTO}

\section{Ingestão de nutrientes e sua relação com a Síndrome da Fragilidade em idosos de uma unidade de Saúde da Família de Ribeirão Preto, São Paulo.}

Dissertação apresentada à Faculdade de Medicina de Ribeirão Preto da Universidade de São Paulo, para obtenção do título de Mestre em Ciências pelo Programa de Pós-Graduação em Saúde Pública.

Orientador: Prof. Dr. Amaury Lelis Dal Fabbro

Ribeirão Preto

2019 
Autorizo a reprodução e divulgação total ou parcial deste trabalho, por qualquer meio convencional ou eletrônico, para fins de estudo e pesquisa, desde que citada a fonte.

Peixoto, Fernando Barbosa

Ingestão de nutrientes e sua relação com a Síndrome da Fragilidade em idosos de uma unidade de Saúde da Família de Ribeirão Preto, São Paulo. 2019.

67 p. : il. ; $30 \mathrm{~cm}$

Dissertação de Mestrado, apresentada à Faculdade de Medicina de Ribeirão Preto/USP. Área de concentração: Saúde Pública.

Orientador: Dal Fabbro, Amaury Lelis. 
Nome: PEIXOTO, Fernando Barbosa

Título: Ingestão de nutrientes e sua relação com a Síndrome da Fragilidade em idosos de uma unidade de Saúde da Família de Ribeirão Preto, São Paulo.

Aprovado em:

Banca Examinadora

Prof. Dr.

Instituição:

Julgamento:

Prof. Dr. Instituição:

Julgamento:

Prof.Dr. Instituição:

Julgamento: 

"O presente trabalho foi realizado com apoio do CNPq, Conselho Nacional de Desenvolvimento Científico e Tecnológico - Brasil”. 


\section{Agradecimentos}

A minha família, por todo apoio quando necessário.

Aos meus amigos, que me ajudaram em diversos momentos e contribuíram para esta conquista.

Ao meu orientador, Prof. Dr. Amaury Lelis Dal Fabbro, pelo aceite, incentivo e principalmente, paciência e compreensão com o meu tempo e modo de trabalho.

A Profa. Dra. Luciana Cisoto Ribeiro, que esteve presente em minha Pós graduação e me auxiliou de forma direta e indireta, em muitos momentos.

A todos os profissionais da Estratégia de Saúde da Família, NSF 3, que sempre me receberam adequadamente para minha coleta de dados.

A todos os idosos que aceitaram participar do meu projeto e contribuíram para o desenvolvimento da ciência, da minha vida profissional, e principalmente, do meu crescimento pessoal. 


\section{Resumo}

\section{Ingestão de nutrientes e sua relação com a Síndrome da Fragilidade em idosos de uma unidade de Saúde da Família, Ribeirão Preto, São Paulo.}

Entende-se por envelhecimento o processo irreversível pela qual passam os seres vivos através da contínua e progressiva diminuição da função celular. Na Estratégia de Saúde da Família o atendimento deve ser humanizado e sobre tudo planejado, e servir assim de porta de entrada adequada para população idosa. Um agravo que vem sendo estudado em muitos países, que também afeta de forma radical a saúde de indivíduos idosos e chega à atenção básica é a Síndrome da Fragilidade, caracterizada por um estado vulnerável da pessoa idosa ocasionado por diminuição da reserva energética e da resistência a agentes agressores, que resulta em uma redução progressiva de diversos sistemas fisiológicos. Desta maneira, o objetivo do presente trabalho foi avaliar a ingestão de nutrientes e a sua relação com a Síndrome da Fragilidade em idosos cadastrados em uma unidade de Saúde da Família no município de Ribeirão Preto, São Paulo. Para a definição de fragilidade foram utilizados os critérios de Fried, onde a pontuação de três critérios ou mais entre os cinco, caracteriza a fragilidade. Pontuações entre um e dois critérios, caracteriza a pré fragilidade e nenhum ponto caracteriza o idoso hígido. Para análise da ingestão de nutrientes foram utilizados dois inquéritos alimentares do tipo recordatório alimentar de 24 horas e o calculo nutricional foi realizado com auxílio do software NutWinß - versão 1.6.0.7. As análises estatísticas foram realizadas por teste paramétrico (t-student) e testes não paramétricos (teste Qui-Quadrado e teste de Mann Whitney), além de análises de contingência (teste exato de Fisher, odds ratio e intervalo de confiença). O nível de significância adotado foi de 95\%, ou seja, $p$ $<0,05$. A prevalência de idosos frágeis encontrada foi de $21 \%$, sendo a maioria dos frágeis idosos do sexo masculino e com idade maior ou igual a 80 anos. Todos os outros $79 \%$ da amostra foram classificados como pré frágeis, pois todos pontuaram ao menos um critério de fragilidade. A doença crônica mais associada com a fragilidade foi a osteoporose. Em relação a ingestão de nutrientes, somente a vitamina C mostrou diferença significativa entre os grupos. $\mathrm{Na}$ análise de contingência das adequações nutricionais, além da vitamina $C$, a vitamina $A$ também obteve diferença significativa entre os grupos. Outros nutrientes mostraram maior ingestão e adequação pelo grupo de pré frágeis, como carboidratos, colesterol, ômega 6 e magnésio, mas sem diferenças significativas. Conclui-se que existe associação positiva entre osteoporose, vitamina $A$ e vitamina $C$ e fragilidade e que são necessários mais estudos com modelo longitudinal prospectivo para melhor elucidar a relação entre a ingestão e adequação nutricional e a fragilidade em idosos da comunidade.

Palavras-chave: Fragilidade. Envelhecimento. Nutrientes. Nutrição em Saúde Pública. Saúde da Família. 


\section{Abstract}

\section{Nutrient intake and the relationship with Frailty Syndrome in the elderly of a Family Health Unit of RibeirãoPreto, São Paulo.}

Aging is understood as the irreversible process through which living beings pass through the continuous and progressive diminution of cellular function. In the Family Health Strategy, care should be humanized and above all planned, and thus serve as an adequate gateway for the elderly population. An affront that has been studied in many countries, which also radically affects the health of elderly individuals and comes to basic care is Frailty, characterized by a vulnerable state of the elderly caused by a decrease in the energy reserve and resistance to aggressive agents, resulting in a progressive reduction of various physiological systems. In this way, the objective of the present study was to evaluate nutrient intake and its relation with Frailty in elderly enrolled in a Family Health unit in the city of Ribeirão Preto, São Paulo. For the definition of frailty Fried criteria were used, where the score of three criteria or more among the five, characterizes the frailty. Scores between one and two criteria, characterize the pre frailty and no point characterizes the elderly healthy. For analysis of nutrient intake, two 24-hour food recall-type food surveys were used and the nutritional calculation was performed using NutWin® software - version 1.6.0.7. Statistical analyzes were performed by parametric test (t-student) and nonparametric tests (Chi-square test and Mann Whitney test), as well as contingency analyzes (Fisher's exact test, odds ratio and confidence interval). The level of significance was $95 \%$, that is, $p<0.05$. The prevalence of frail elderly was found to be $21 \%$, with the majority of the fragile elderly being males older than or equal to 80 years of age. All the other $79 \%$ of the sample were classified as pre-fragile, since all scored at least one criterion of fragility. The chronic disease most associated with frailty was osteoporosis. In relation to nutrient intake, only vitamin C showed a significant difference between the groups. In the contingency analysis of nutritional adequations, besides vitamin $\mathrm{C}$, vitamin $\mathrm{A}$ also obtained a significant difference between the groups. Other nutrients showed higher intake and adequacy by the group of pre frailty ones, such as carbohydrates, cholesterol, omega- 6 and magnesium, but without significant differences. It was concluded that there is a positive association between osteoporosis, vitamin $\mathrm{A}$ and vitamin $\mathrm{C}$ and fragility and that more studies with a prospective longitudinal model are needed to better elucidate the relationship between intake and nutritional adequacy and frailty in the elderly in the community.

Keywords: Frailty. Aging. Nutrients. Nutrition, Public Health. Family Health. 


\section{Lista de siglas}

$\begin{array}{ll}\text { PNSPI } & \text { Politica Nacional de Saúde da Pessoa Idosa } \\ \text { DCNT } & \text { Doenças Crônicas não Transmissíveis } \\ \text { ESF } & \text { Estratégia de Saúde da Família } \\ \text { IC } & \text { Intervalo de Confiança } \\ \text { DP } & \text { Desvio Padrão } \\ \text { IMC } & \text { Índice de Massa Corporal } \\ \text { AVD's } & \text { Atividades de Vida Diária } \\ \text { CBFI } & \text { Consenso Brasileiro de Fragilidade em Idosos } \\ \text { OST } & \text { Osteoporose } \\ \text { TMB } & \text { Taxa Metabólica Basal } \\ \text { GET } & \text { Gasto Energético Basal } \\ \text { APS } & \text { Atenção Primária à Saúde } \\ \text { TCLE } & \text { Termo de Consentimento Livre e Esclarecido } \\ \text { DRI's } & \text { Dietary Reference Intakes } \\ \text { DM } & \text { Diabetes Melittus } \\ \text { HAS } & \text { Hipertensão Arterial Sistêmica } \\ \text { DIS } & \text { Dislipidemia } \\ \text { OR } & \text { Odds ratio } \\ \text { SIDA } & \text { Síndrome da Imuno Deficiência Adquirida }\end{array}$




\section{Sumário}

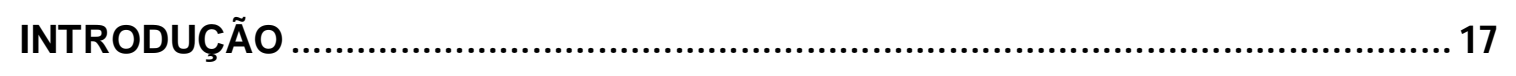

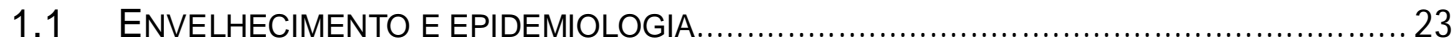

1.2 ENVELHECIMENTO NO CONTEXTO DA ATENÇÃO BÁSICA.......................................... 18

1.3 SINDROME DA FRAGILIADE E INSTRUMENTOS DE AVALIAÇÃO............................... 19

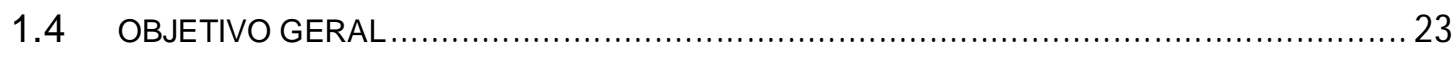

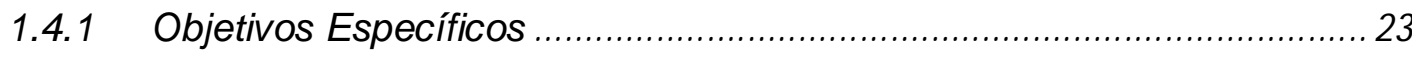

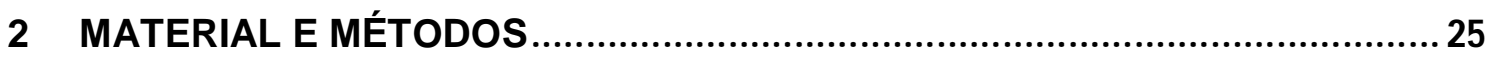

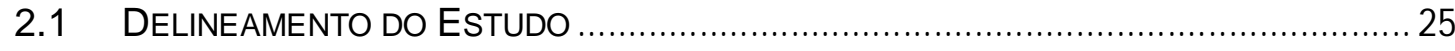

2.2 CONTEXTO

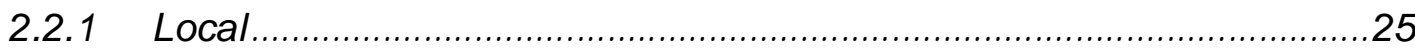

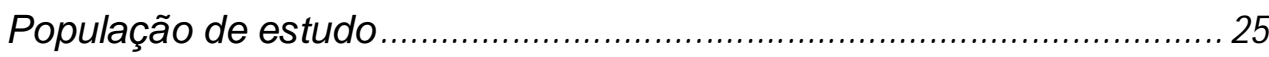

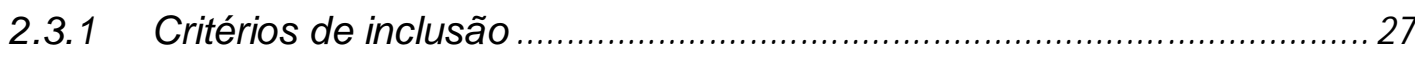

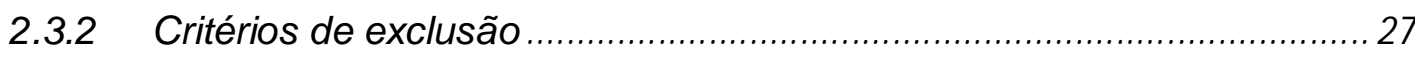

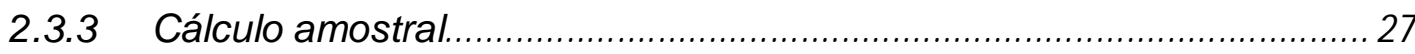

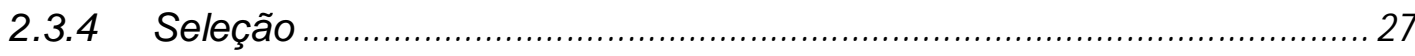

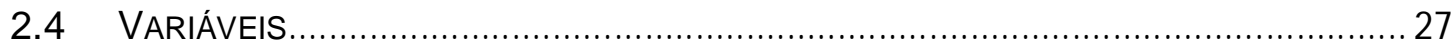

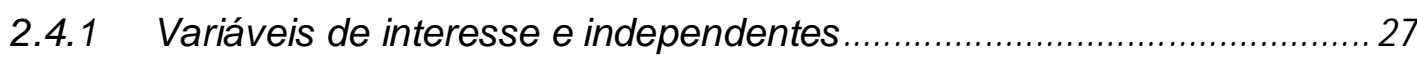

2.4.2 Variáveis de controle para Fragilidade - dependentes.............................. 27

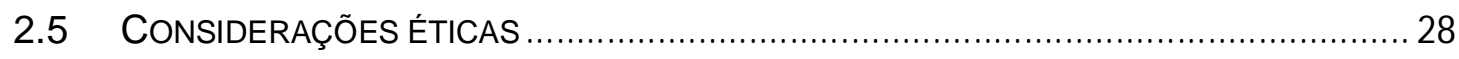

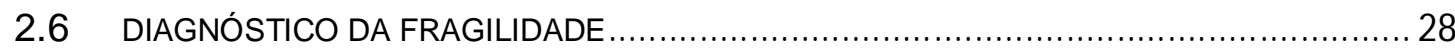

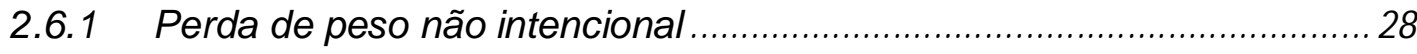

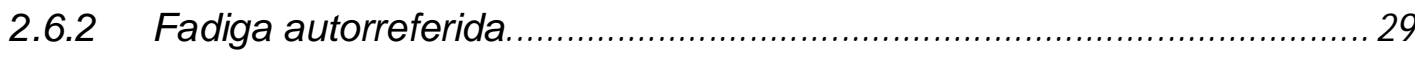

2.6.3 Diminuição da força de preensão manual............................................... 29

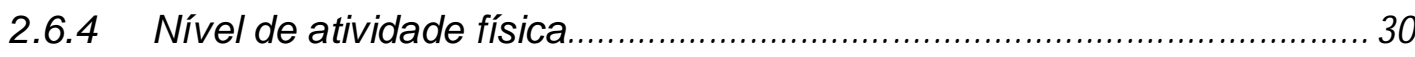

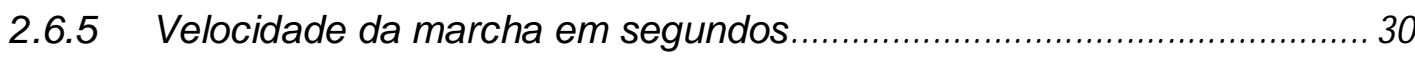

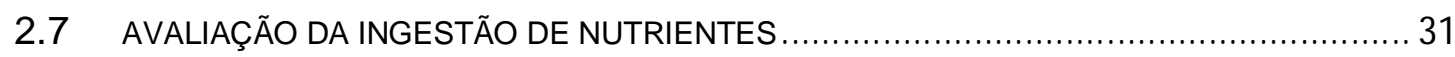

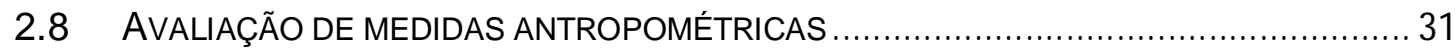

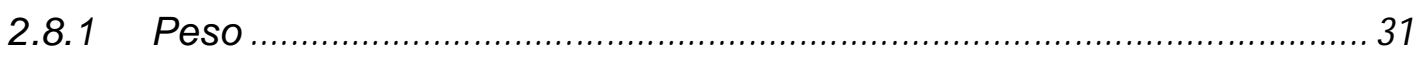

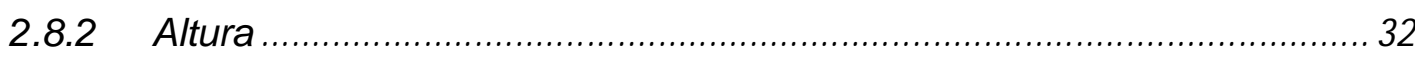

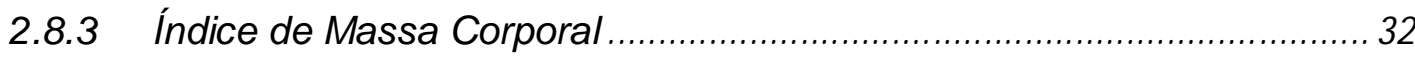

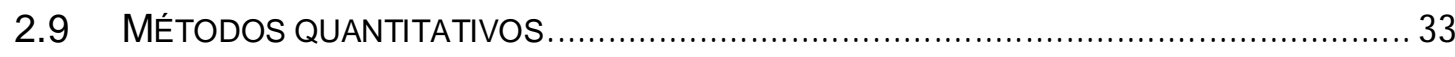




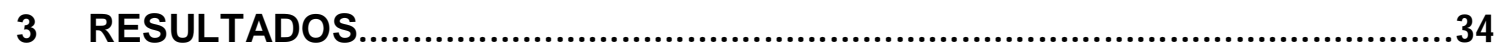

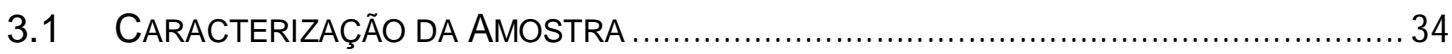

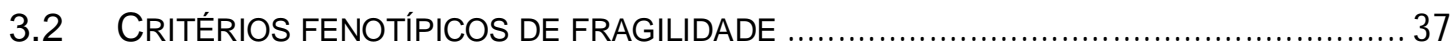

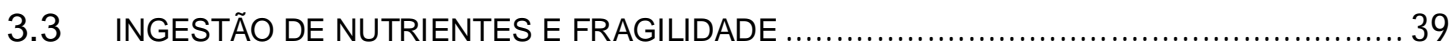

4 DISCUSSÃO.

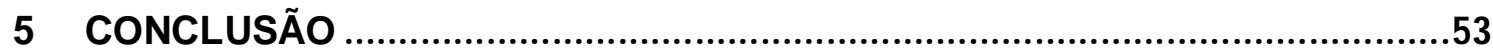

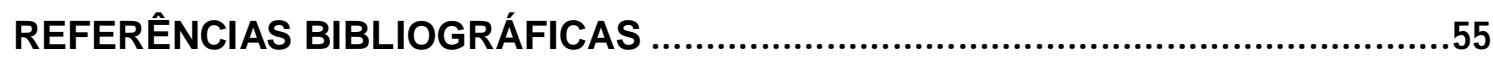

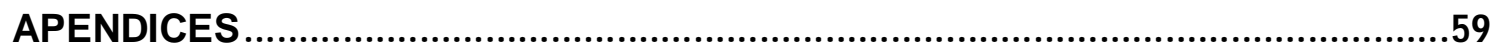

ANEXOS 


\section{Capítulo 1}

\section{Introdução}

\subsection{Envelhecimento e Epidemiologia}

Entende-se por envelhecimento o processo irreversível pela qual passam os seres vivos através da contínua e progressiva diminuição da função celular (MAZO; LOPES; BENEDETTI, 2009). Com a redução da atividade celular o organismo sofre perdas graduais da reserva fisiológica e maior risco no desenvolvimento de doenças, e ao final desse processo culmina em morte (OMS, 2015). Ocorrem alterações bioquímicas, morfológicas, anatômicas, psicológicas e funcionais, que ocasionam uma menor adaptação do indivíduo ao meio ambiente, que além de elevar a prevalência de doenças agudas e crônicas, gera maior instabilidade social, econômica e funcional desses indivíduos (DE CARVALHO FILHO, 2002; ELIOPOULOS, 2010). A Organização Pan-Americana de Saúde (OPAS) define o envelhecimento como:

Um processo sequencial, individual, acumulativo, irreversível, universal, não patológico, de deterioração de um organismo maduro, próprio a todos os membros de uma espécie, de maneira que o tempo o torne menos capaz de fazer frente ao estresse do meioambiente e, portanto, aumente sua possibilidade de morte (BRASIL, 2006, p.08).

O envelhecimento populacional cresce em caráter expressivo em muitos países desenvolvidos e principalmente, nos países em desenvolvimento (WHO, 2002; VERAS, 2003; OMS, 2015). No Brasil, o aumento da esperança de vida e a redução das taxas de fecundidade e mortalidade contribuem para a transição da pirâmide demográfica do país (IBGE, 2011). Esse elevado aumento da longevidade, por um lado é considerado mérito social e de saúde, através da melhoria nas condições sociais e na evolução na prevenção e tratamento de doenças. Por outro lado, o aumento da população de idosos é um verdadeiro desafio para o país, ao 
considerar a necessidade contínua de investimentos em políticas públicasde saúde, urbanismo, previdência e muitos outros serviços essenciais para o bem estar da pessoa idosa (GORDILHO et al., 2000; WHO, 2005; MELLO et al., 2009).

São muitos os agravos decorrentes do processo de envelhecimento humano. O envelhecimento, quando apresenta diminuição progressiva da reserva funcional, o que se conhece como senescência, comumente não traz problemas. A senescência, ao contrário do que muitos pensam, não se traduz em doença, o que no caso é conhecido como senilidade, ou seja, são os agravos à saúde do idoso como doenças, acidentes e estresse que geram demandas por assistência (BRASIL, 2006).

\subsection{Envelhecimento no contexto da Atenção Básica}

A porta de entrada para a atenção à saúde da pessoa idosa, preconizada pela Política Nacional de Saúde da Pessoa Idosa (PNSPI), Portaria GM no 2.528, de 19 de outubro de 2006, indica a Atenção Básica, seja Unidades Básicas de Saúde tradicionais ou Estratégias de Saúde da Família, como promotora e receptora deste público, tendo os níveis secundário e terciário de atenção à saúde como apoio e referência (BRASIL, 2006; BRASIL, 2017).

Na Estratégia de Saúde da Família o atendimento deve ser humanizado e sobre tudo planejado. O planejamento é uma característica fundamental para o acolhimento dos idosos e suas redes de apoio, quando existente, bem como para o desenvolvimento de ações pró-ativas e humanizadas (BRASIL, 2006; BRASIL, 2017). Essa condição torna a Estratégia de Saúde da Família um importante campo de acolhimento, cuidado e monitoramento da saúde da pessoa idosa, o que exige deste sistema constante atualização sobre os agravos naturais e ambientais do envelhecimento.

Em termos de saúde, a autonomia e funcionalidade dos idosos são uma ferramenta eficiente para o envelhecimento bem sucedido. No entanto, muitas são as complicações que podem afetar a funcionalidade dos idosos e com isso limitar sua autonomia. As Doenças Crônicas Não Transmissíveis (DCNT) como diabetes, osteoporose e doenças cardiovasculares, por exemplo, afetam a funcionalidade de idosos e elevam cerca de $5 \%$ a dependência para a realização das Atividades de 
Vida Diária (AVD's) em idosos na faixa etária de 60 anos e até $50 \%$ na faixa etária dos 90 anos (BRASIL, 2006). Outro agravo, que vem sendo estudado em muitos países, que também afeta de forma radical a funcionalidade em indivíduos idosos é a Síndrome da Fragilidade.

\subsection{Síndrome da Fragilidade e Instrumentos de Avaliação}

A Síndrome da Fragilidade vem sendo estudada nos últimos anos, no entanto, ainda apresenta um déficit em relação a sua definição, que não ocorre de maneira consensual (TEIXEIRA, 2012).

Acredita-se que a Síndrome apresenta-se sobre uma condição multidimensional, através de uma interação complexa entre diversos sistemas, entre eles o biológico, psicológico e o social, que resulta em maior vulnerabilidade, levando ao maior risco de desfechos clínicos não desejados, como fraturas, declínio funcional, hospitalização, institucionalização ou até morte (BRASIL, 2006).

Fried et al., (2001), define a Síndrome da Fragilidade como um estado vulnerável da pessoa idosa ocasionado por diminuição da reserva energética e da resistência a agentes agressores, que resulta em uma redução progressiva de diversos sistemas fisiológicos.

De acordo com o consenso internacional, a fragilidade é uma condição clínica de etiologia multifatorial, que torna o indivíduo mais vulnerável, e com maiores chances de dependência e mortalidade (MORLEY, et al., 2013).

Para o Consenso Brasileiro de Fragilidade em Idosos (CBFI), a fragilidade se refere a uma vulnerabilidade fisiológica ligada a idade, caracterizada por uma homeostase reduzida, que resulta em diminuída capacidade do organismo em lidar com desfechos clínicos negativos (LOURENÇO et al., 2018).

Fried et al., (2001), define a Síndrome da Fragilidade como um estado vulnerável da pessoa idosa ocasionado por diminuição da reserva energética e da resistência a agentes agressores, que resulta em uma redução progressiva de diversos sistemas fisiológicos.

Atualmente, existem três modelos conceituais mais utilizados em diagnósticos clínicos e em pesquisas no Brasil. O primeiro modelo, referente aos critérios de Fried 
ou Escala de Fragilidade do Cardiovascular Health Study (EFCHE), trata-se do modelo de fragilidade fisiológica, que define características fenotípicas mensuráveis relacionadas ao estado nutricional, gasto energético, exercícios físicos e força e mobilidade. O segundo modelo, trata-se do índice de Fragilidade de Rockwood ou Escala de Fragilidade Clínica, que avalia a somatória de déficits clínicos. Já o terceiro modelo, conhecido como Escala de Edmonton, que abrange um estado clínico de perdas multidimensionais, como aspectos físicos, cognitivos e sociais (LOURENÇO et al., 2018).

A Fragilidade em idosos pode colocar em risco uma série de outros aspectos de saúde, pois um indivíduo frágil se limita em suas atividades instrumentais como ter acessibilidade física aos alimentos, cozinhar, alimentar-se, organizar e administrar suas medicações, realizar sua higiene pessoal, entre outras atividades que em condições inadequadas afetam diretamente a saúde de um indivíduo. A Pesquisadora dos Estados Unidos (EUA) Dra. Linda Fried, juntamente com seus colaboradores da John Hopkins University, trabalham com a síndrome da fragilidade e seus aspectos objetivos, ou seja, pesquisam condições fenotípicas que podem sugerir os primeiros sinais de desenvolvimento da síndrome, para que assim se possa intervir precocemente e evitar a instalação da síndrome e redução na incidência da doença (BRASIL, 2006).

De acordo com as pesquisas de Fried et al., (2001), com americanos participantes do Cardiovascular Health Study, a fragilidade em idosos pode ser detectada pela investigação de cinco condições fenotípicas mensuráveis: perda de peso não intencional; fadiga auto referida; diminuição da força de preensão; baixo nível de atividade física e diminuição da velocidade da marcha. Com o estudo, foi verificado que os idosos que se encaixam em três ou mais critérios são considerados frágeis. A presença de um ou dois critérios se caracteriza como idoso pré-frágil e nenhum critério classificado como ausência ou baixa chance de desenvolvimento da fragilidade.

A associação de fatores causados pela idade com fatores relacionados às doenças permite relacionar algumas complicações que podem resultar no início do processo de fragilização, essas alterações ficaram conhecidas como a "tríade da fragilidade" que se constitui por: sarcopenia; desregulação neuroendócrina e disfunção imunológica (FRIED et al., 2001). Subnutrição crônica também pode iniciar o processo de fragilidade (BRASIL, 2006). 
Percebe-se que os critérios fenotípicos mensuráveis estão intimamente ligados à composição corporal do individuo, que por sua vez, está relacionada à ingestão energética. Conforme já proposto por Teixeira (2006) a ingestão alimentar pode ilustrar um dos agentes causais iniciais do ciclo da fragilidade. Na figura 1 encontra-se o ciclo da fragilidade hipotetizado por Fried et al., (2001) com bases em consistentes associações de sinais clínicos e sintomas da fragilidade.

Figura 1 - Ciclo da fragilidade hipotetizado com base em sinais e sintomas da fragilidade

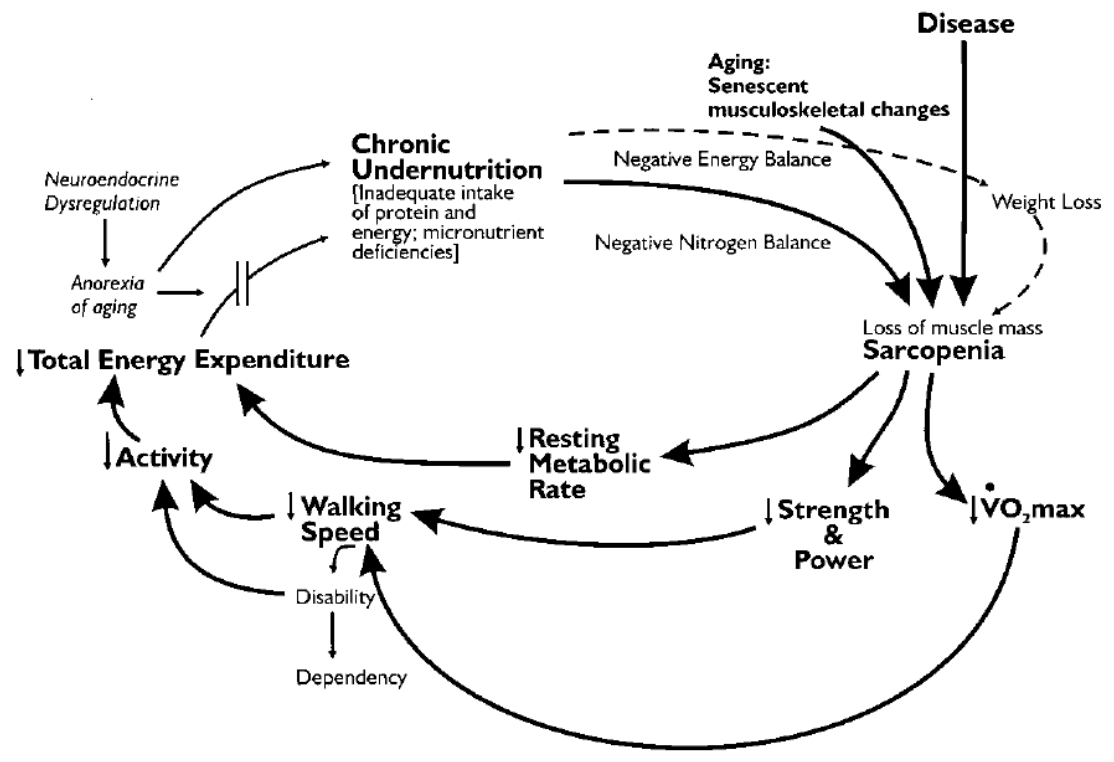

Fonte: Fried et al., (2001)

Na figura acima é possível perceber um ciclo de difícil controle, onde a desnutrição crônica, o envelhecimento e doenças levam a sarcopenia, que por sua vez reduz a taxa metabólica basal (TMB), reduz o $\mathrm{VO}^{2}$ máximo e reduz a força, a redução do $\mathrm{VO}^{2}$ máximo reduz a velocidade da marcha que reduz a atividade física. A redução da TMB e da velocidade da marcha reduzem o gasto energético total (GET), que piora a desnutrição crônica. A adequada ingestão energética, proteica e de micronutrientes, apresentam um balanço positivo em relação à saúde do idoso e minimização da desnutrição crônica.

O tecido muscular possui uma relação direta com baixa tolerância ao exercício, diminuição da força muscular, elevada fadiga e fraqueza. A diminuição da força compromete equilíbrio, marcha e eleva as quedas (DUARTE \&LEBRÃO, 2011). 
Já em relação à saúde óssea, sabe-se que sua ligação com o sistema neuroendócrino the causa uma série de complicações que podem influenciar no desenvolvimento da fragilidade em idosos. Estudos mostram que uma diminuição nos níveis do hormônio de crescimento (inerente ao envelhecimento), exposições prolongadas a elevados níveis de cortisol (geradas pela resposta do organismo a agentes estressores) e perda acentuada de estrógenos (ocasionada pela menopausa) são fatores que afetam negativamente a saúde óssea e agem diretamente na instalação do ciclo da fragilidade, levando à incapacidade funcional do idoso, que eleva sua vulnerabilidade aos estressores e reduz sua capacidade de adaptação (DUARTE \& LEBRÃO, 2011).

Poucos estudos internacionais são encontrados a respeito da relação entre ingestão de nutrientes e fragilização em idosos. No Brasil, nenhum estudo específico sobre ingestão de nutrientes relacionados à síndrome da fragilidade foi encontrado durante o levantamento bibliográfico.

Como exemplo da importância da intersecção da nutrição com a fragilidade, Beasley et al., (2010) estudou a ingestão de proteínas por idosas americanas com idade entre 65 e 79 anos e constatou que um consumo de $20 \%$ ou mais do valor energético total diário está associado a um baixo risco de fragilidade. Já um estudo com idosos italianos verificou que a baixa ingestão de vitaminas D, E, C, B9, B12 e proteínas associam-se significativamente com a síndrome da fragilidade (BARTALI, 2006). Outros nutrientes como selênio e zinco e também compostos bioativos, como carotenóides, já foram associados à fragilidade quando consumidos em baixas quantidades (MELLO et al., 2014 apud MICHELON et al., 2006; SEMBA et al., 2006).

Com todo o exposto, acredita-se que a identificação de idosos vulneráveis ao desenvolvimento da Síndrome da Fragilidade, através da identificação dos agravos iniciais, pode favorecer o retardamento e a progressão da síndrome bem como, proporcionar um tratamento adequado dentro dos serviços de saúde. Assim, a Atenção Primária à Saúde (APS), através da Estratégia de Saúde da Família, pode atuar neste cenário, através de um adequado planejamento e contínua atualização e pesquisa. 


\subsection{Objetivo Geral}

Avaliar a ingestão de nutrientes e a sua relação com a Síndrome da Fragilidade em idosos cadastrados em uma unidade de Saúde da Família no município de Ribeirão Preto, São Paulo.

\subsubsection{Objetivos Específicos}

- Identificar a prevalência da Síndrome da Fragilidade entre os idosos participantes do estudo;

- Quantificar a ingestão de macro e micronutrientes dos idosos participantes do estudo;

- Verificar a adequação da ingestão nutricional em relação às DRl's;

- Verificar a significância entre as diferenças das médias de ingestão nutricional entre os grupos;

- Testar e verificar as chances de causalidade bilateral entre a condição de fragilidade e a exposição, sendo a exposição a inadequação da ingestão nutricional em relação as DRl's;

- Testaras variáveis independentes de sexo, idade, índice de massa corporal e DCNT autorreferidas com a condição de fragilidade. 



\section{Capítulo 2}

\section{Material e Métodos}

\subsection{Delineamento do Estudo}

Trata-se de um estudo observacional descritivo e analítico, de corte transversal.

\subsection{Contexto}

\subsubsection{Local}

O estudo foi realizado com idosos cadastrados em uma unidade de Estratégia de Saúde da Famíliado município de Ribeirão Preto, São Paulo.

\subsection{População de Estudo}

A população utilizada para a pesquisa originou-se de uma amostra sorteada aleatoriamente entre os idosos cadastrados na ESF.

A ESF, local da coleta dos dados, possui uma prevalência elevada de usuários idosos como característica marcante. Atualmente, a população de usuários cadastrados é de 2000 indivíduos, sendo que destes, 606 (30,3\%) são idosos. 


\subsubsection{Critérios de inclusão:}

Os critérios de inclusão foram: idosos com 60 anos ou mais, de ambos os sexos, residentes na área de abrangência da unidade de Saúde da Família e que aceitem participar do estudo através da assinatura do termo de consentimento livre e esclarecido (apêndice 1) pelo próprio ou representante legal.

\subsubsection{Critérios de exclusão:}

Os critérios de exclusão foram: idosos com diagnósticos de doenças neurodegenerativas como Parkinson, Alzheimer ou Demências vasculares; doenças psiquiátricas graves como Esquizofrenia, Transtorno Afetivo Bipolar e Depressão grave; com diagnóstico de doenças terminais como câncer ou SIDA; deficientes físicos, visuais ou auditivos e acamados. Estes perfis não foram avaliados pelo estudo devido à possibilidade de seu padrão alimentar estar alterado nos últimos tempos e também, em alguns casos, a impossibilidade de aplicação dos testes físicos.

\subsubsection{Cálculo Amostral}

Para o cálculo amostral foi realizado conforme equação de Lwanga \& Lemeshow (1991), onde $N=(P \times Q) /(E / Z \alpha)^{2}$

Onde:

$\mathrm{N}=$ Amostra a ser pesquisada;

$Z \alpha^{2}=(1,96)^{2}$ para um intervalo de confiança de $95 \%$;

$\mathrm{P}=$ Prevalência de Fragilidade - utilizou-se 11\% (estudos nacionais e internacionais encontraram prevalência entre 7 e 15\%);

$\mathrm{Q}=$ Complemento;

$\mathrm{E}=$ Erro amostral de tolerância, considerou-se 7\%;

Sendo então: $\quad N=(11 \times 89) /(7 / 1,96)^{2}$

$\mathrm{N}=(900) /(12,75)$

$\mathrm{N}=77$ indivíduos 


\subsubsection{Seleção}

Levando em consideração as perdas, por não encontrar o usuário em sua residência ou a não aceitação em participar do estudo, foi acrescido $50 \%$ do total no sorteio, sendo sorteados de forma aleatória 115 idosos cadastrados.

\subsection{Variáveis}

\subsubsection{Variáveis de interesse (independentes)}

I - Dados de caracterização da amostra

- Idade (anos completos)

- Sexo

II - Características/Informações pessoais e de saúde.

- Peso

- Altura

- IMC

- Doenças crônicas autorreferidas (HAS, DM, DIS, OST)

- Ingestão de nutrientes

\subsubsection{Variáveis de controle para fragilidade (dependentes)}

- Prática de atividade física

- Velocidade da marcha

- Força de preensão manual

- Fadiga autorreferida

- Perda de peso não intencional 


\subsection{Considerações Éticas}

O estudo foi submetido e aprovado pelo Comitê de Ética em Pesquisa do Centro de Saúde Escola Dr. Joel Domingos Machado, sob o número CAAE 46509815.2.0000.5414. Também foi submetido e aprovado pela Estratégia de Saúde de Família campo do estudo. Todos os indivíduos participantes assinaram o TCLE.

\subsection{Diagnóstico da Síndrome da Fragilidade}

O diagnóstico de Fragilidade para este estudo seguiu os critérios de Fried, que estabeleceu critérios fenotípicos mensuráveis.

Foram mensuradas cinco características fenotípicas (perda de peso não intencional, fadiga autorreferida, nível de atividade física, força muscular e velocidade da marcha), por métodos propostos pelos pesquisadores. A entrevista para avaliação da fragilidade e consumo alimentar foi conduzida de acordo com questionário pré-estabelecido (apêndice 2). Em alguns casos foram coletadas informações como dados cadastrais; informações de contato e outras variáveis de interesse, através do prontuário de saúde do usuário.

\subsubsection{Perda de peso não intencional}

A perda de peso não intencional foi avaliada de duas maneiras. A primeira foi através da pergunta: "O Sr.(a) perdeu 4,5 kg ou mais no último ano?", se a resposta for sim, o indivíduo preencheu este critério para fragilidade. Mas, se caso o idoso não sabia mensurar ao certo sua perda, foi realizada a seguinte pergunta: "Quanto o Sr.(a) pesava nessa mesma época no ano passado?", através da resposta o valor foi comparado ao peso atual. Se a diferença for maior ou igual a $4,5 \mathrm{~kg}$ ou $5 \%$ de perda, também foi preenchido o critério para fragilidade (FRIED, 2001). 


\subsubsection{Fadiga autorreferida}

A fadiga autorreferida foi avaliada através da escala de depressão do Center for Epidemiological Studies (CES-D), como proposto por Fried et al., (2001), já validado para população brasileira idosa (BATISTONI, et al. 2010). A CES-D (anexo 1) é composta por 20 itens sobre sintomas somáticos, humor e funcionamento motor e as respostas são em escala Likert: nunca ou raramente $=0$ ( $>1$ dia); às vezes $=1$ (1 a 2 dias); frequentemente $=2$ (3 a 4 dias); sempre $=3$ (diariamente). Para a avaliação da fadiga autorreferidaforam utilizados os itens que avaliam características somáticas, que são: "senti que tive que fazer esforço para fazer tarefas habituais" e "Não consegui levar adiante minhas tarefas habituais". Os idosos que obtiveram escore 2 ou 3, para qualquer uma das duas questões, preencheram o critério para fragilidade (FRIED, 2001).

\subsubsection{Diminuição da força muscular}

A diminuição da força muscular foi avaliada através da verificação de força de preensão palmar, avaliada por Dinamômetro hidráulico de mão, modelo Sanny, com escala de 0 a $100 \mathrm{~kg} / \mathrm{f}$. O teste foi realizado com o idoso sentado, com ombro aduzido, cotovelo fletido à $90^{\circ}$, antebraço em posição neutra e punho entre 0 e $30^{\circ}$. Foi dado um comando verbal para o idoso apertar e segurar por seis segundos. Foram obtidas três medidas em quilograma/força (Kgf) e foi utilizado no estudo a maior mediada entre as três aferições (HAIDAR, et al., 2004). Os pontos de corte para este critério foram os mesmos propostos por Fried et al., (2001), conforme tabela 1. Os valores obtidos foram ajustados para sexo e IMC, sendo que o último foi ajustado por intervalo interquartil.

\begin{tabular}{|c|c|c|c|}
\hline Homens & \multicolumn{3}{|c|}{ Mulheres } \\
\hline IMC & Pontos de corte & IMC & Pontos de corte \\
\hline$\leq 24$ & $\leq 29$ & $\leq 23$ & $\leq 17$ \\
\hline $24,1-26$ & $\leq 30$ & $23,1-26$ & $\leq 17,3$ \\
\hline $26,1-28$ & $\leq 30$ & $26,1-29$ & $\leq 18$ \\
\hline$>28$ & $\leq 32$ & $>29$ & $\leq 21$ \\
\hline
\end{tabular}

Fonte: Fried et al., (2001) 


\subsubsection{Nível de atividade física}

O nível de atividade física foi avaliado pela versão validada e adaptada para idosos brasileiros (anexo 2) (BENEDETTI, 2007 e 2008) do Questionário Internacional de Atividade Física (International Physical Activity Questionnaire IPAQ). O IPAQ avalia a quantidade total de minutos por semana de realização de atividade física, separada em quatro dimensões, sendo: atividade física no trabalho, atividade física como meio de transporte, atividade física em tarefas domésticas e atividade física como lazer. Cada dimensão pode apresentar diferentes intensidades de atividade física, que podem variar entre leve, moderada e vigorosa.

Preencheram o critério de fragilidade os idosos que, segundo o IPAQ, foram considerados inativos, ou sedentários. O ponto de corte utilizado para ser considerado ativo foi de no mínimo 150 minutos por semana de atividade física, conforme recomendações do American College of Sports Medicine e da Orgnização Mundial de Saúde (PATE et al., 1995; OMS, 2015).

\subsubsection{Velocidade da marcha em segundos}

Para avaliar a velocidade da marcha foi realizada a cronometragem (em segundos) da caminhada em velocidade confortável. O percurso de 8,6 metros foi sinalizado no chão, sendo que a distância medida foi para 4,6 metros, pois os dois primeiros e dois últimos metros são para adequação da marcha. As medidas obtidas foram ajustadas para sexo e altura e os pontos de corte adotados para este critério foram os propostos por Fried et al., (2001), como mostra na tabela 2. Os idosos que ultrapassaram os pontos de corte, preencheram este critério para a fragilidade.

Tabela 2 - Pontos de corte para velocidade da marcha

\begin{tabular}{cccc}
\hline Homens & \multicolumn{3}{c}{ Mulheres } \\
Altura & Pontos de corte & Altura & Pontos de corte \\
\hline$\leq 1,73$ & $\geq 7$ & $\leq 1,59$ & $\geq 7$ \\
$>1,73$ & $\geq 6$ & $>1,59$ & $\geq 6$ \\
\hline
\end{tabular}

Fonte: Fried et al., (2001) 


\subsection{Avaliação da ingestão de nutrientes}

A ingestão alimentar foiavaliada através da aplicação de inquérito alimentar já validado, do tipo Recordatório Alimentar de 24 horas (KARVETTI \& KNUTS, 1985).

Foram aplicados 2recordatórios de 24 horas, em dias típicos da semana. Para a quantificação da ingestão de macro e micronutrientes foi considerada a média de ingestão entre os 2 dias.

Para a melhor mensuração de quantidades alimentares ingeridas por porção de alimentos, no momento da aplicação do inquérito alimentar, foi solicitado ao usuário que mostrasse os utensílios utilizados em suas refeições, fato que só foi possível devido ao inquérito alimentar ser colhido na residência do usuário.

O cálculo da ingestão de nutrientesfoi realizado com o auxílio do software da Universidade Federal de São Paulo (UNIFESP), Programa de Apoio à Nutrição versão 1.6.0.7 - NutWin ${ }^{\circledR}$. A base de dados contendo as quantidades centesimais de nutrientes dos alimentos foi do próprio software, que também foiatualizado com alimentos faltantes, extraídos das tabelas de composição de alimentos: Tabela para Avaliação de Consumo Alimentar em Medidas Caseiras (PINHEIRO, 2000) e Tabela Brasileira de Composição de Alimentos - TACO 4ª edição (TACO, 2011).

\subsection{Avaliação de medidas antropométricas}

\subsubsection{Peso}

Para a aferição do peso corporal atual do participante, foi utilizada balança digital portátil da marca G-Tech, modelo Glass 200 Control, com capacidade de até $200 \mathrm{~kg}$. Para a avaliação do peso corporal foram seguidas as seguintes etapas (IBGE, 2013):

a) O participante estava vestindo roupas leves, descalço, com os bolsos vazios e sem adornos; 
b) Foi solicitado que o participante subisse na balança, com os dois pés apoiados na plataforma e o peso distribuído entre ambos os pés;

c) O participante não deve estar olhando para o visor da balança, e sim para a linha do horizonte;

d) O valor foi registrado na ficha de avaliação;

e) Foi solicitado que o participante descesse da balança;

\subsubsection{Altura}

Para a aferição da altura foi utilizadofita métrica inelástica fixa a parede, com 200 centímetros de comprimento, em escala de milímetros e centímetros. Para a avaliação daaltura foram seguidas as seguintes etapas (IBGE, 2013):

a) O indivíduo estava descalço ou de meias;

b) Com o indivíduo em pé, pernas paralelas ao corpo e braças estendidos com as mãos voltadas para o corpo;

c) Costas voltadas para a parede;

d) Encostados na parede calcanhares, panturrilhas, nádegas, costas e cabeça;

e) Posicionamento da cabeça no plano de Frankfurt;

\subsection{3 Índice de Massa Corporal (IMC)}

Com as medidas de peso e altura, foi calculado o índice de massa corporal a partir da fórmula: $I M C=$ Peso $(\mathrm{kg}) /$ Altura $^{2}(\mathrm{~m})$. De acordo com o valor do IMC os idosos foram alocados conforme classificação proposta por Nutrition Screening Initiative (NUTRITION, 1994), cujos pontos de corte, expressos na tabela 3, são os mesmos utilizados no Brasil pelo Sistema de Vigilância Alimentar e Nutricional (SISVAN) (MINISTÉRIO DA SAÚDE, 2011).

Tabela 3 -Classificação do IMC

\begin{tabular}{cc}
\hline IMC & Classificação \\
\hline$<22 \mathrm{~kg} / \mathrm{m}^{2}$ & Baixo Peso \\
22 a $27 \mathrm{~kg} / \mathrm{m}^{2}$ & Eutrofia \\
$>27 \mathrm{~kg} / \mathrm{m}^{2}$ & Excesso de Peso \\
\hline Fonte: Nutrition Screening Initiative, (2001)
\end{tabular}




\subsection{Métodos Quantitativos}

Os resultadosforam descritosna forma de frequências simples e/ou relativas e organizados em tabelas de contingência. Foram calculados a média e desvio padrão das variáveis contínuase percentuais das variáveis categóricas com auxílio do Programa Office Excel® 2019.

A análise estatísticafoirealizada com auxílio do programa Prisma 5.03. Para testar a normalidade dos dados foi utilizado o teste de Kolmogorov Smirnov. Para a comparação entre duas variáveis com distribuição normal foi utilizado teste de TStudent para amostras independentes, e para a comparação entre duas variáveis de distribuição não normal, foi utilizado o teste de Mann Whitney para dados não paramétricos. Nas análises de três ou mais variáveis independentes com distribuição não paramétrica, foi utilizado o teste Qui-Quadrado. Para as análises de contingência de dados não paramétricos foi utilizado o teste Exato de Fisher. Ainda, para análises de contingênciarelacionada à adequação nutricional e teste de chances entre os grupos, foi utilizado odds ratio e seu respectivo intervalo de confiança. O nível de significância adotado em todas as análises foi de $95 \%$, ou seja, $p<0,05$. 


\section{Capítulo 3}

\section{Resultados}

\subsection{Caracterização da Amostra}

No total foram avaliados pelo estudo 76 idosos cadastrados na unidade de Estratégia de Saúde da Família de referência para a coleta, conforme mostra o fluxograma abaixo:

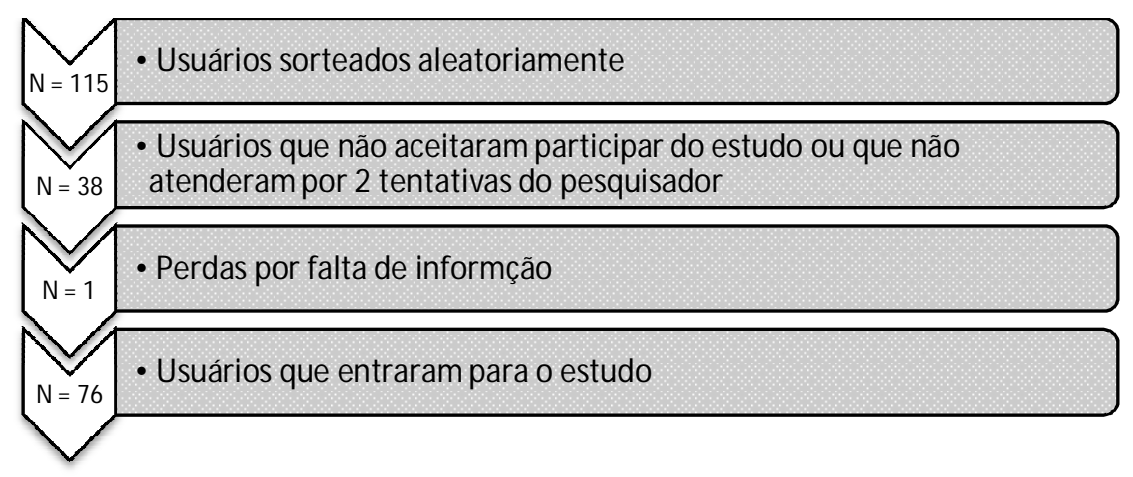

Os resultados referentes à caracterização da amostra estão sumarizados na tabela 4 . O número total de participantes inseridos no estudo, após as perdas por não aceitação de participação, ausência no domicílio em duas tentativas pelo pesquisador e perda por falta de informações no questionário, foi de 76 usuários regularmente cadastrados na ESF de referência, uma representatividade de $12,5 \%$ dos idosos cadastrados na unidade.

Dos 76 participantes, 27 (35,5\%) foram do sexo masculino e 49 (64,5\%) eram do sexo feminino. É evidente a diferença entre o número total de homens e mulheres no estudo, no entanto, ao alocar os idosos entre os dois grupos de estudo, os frágeis e os pré frágeis, a proporção de cada sexo dentro de cada grupo se torna muito próxima, sendo no grupo de frágeis a prevalência de 22,2\% de homens e $20,4 \%$ de mulheres, e no grupo de pré frágeis $77,8 \%$ de homens e 
79,6\% de mulheres. Diferença esta que não demonstrou significância estatística, sendo $p>0,05$.

Tabela 4. Caracterização da amostra

Variáveis Pré Frágil

Sexo

Masculino

Feminino

Total

Faixa Etária

Média (DP)

Masculino

60-79

$\geq 80$

Feminino

$60-79$

$\geq 80$

IMC

Média (DP)

$<2$

22-27

$>27$

\section{Comorbidades}

Diabetes

\begin{tabular}{|c|c|c|c|c|c|c|c|}
\hline Sim & 18 & 81,8 & 4 & 18,2 & 22 & 28,9 & \\
\hline Não & 42 & 65,6 & 12 & 18,8 & 54 & 84,2 & $0,767 *$ \\
\hline \multicolumn{8}{|c|}{ Hipertensão Arterial } \\
\hline Sim & 37 & 77,1 & 11 & 22,9 & 48 & 63,2 & \\
\hline Não & 23 & 82,1 & 5 & 17,9 & 28 & 36,8 & $0,772 *$ \\
\hline \multicolumn{8}{|c|}{ Dislipidemia } \\
\hline Sim & 40 & 85,1 & 7 & 14,9 & 47 & 61,8 & \\
\hline Não & 20 & 69,0 & 9 & 31,0 & 29 & 38,2 & $0,146^{*}$ \\
\hline \multicolumn{8}{|c|}{ Osteoporose } \\
\hline Sim & 20 & 66,7 & 10 & 33,3 & 30 & 39,5 & \\
\hline Não & 40 & 87,0 & 6 & 13,0 & 46 & 60,5 & $0,045^{*}$ \\
\hline
\end{tabular}

$\begin{array}{ccccccc}21 & 77,8 & 6 & 22,2 & 27 & 35,5 & \\ 39 & 79,6 & 10 & 20,4 & 49 & 64,5 & 1^{*} \\ 60 & & 16 & & 76 & 100 & \end{array}$

$74,9 \pm 8,0 \quad 81,1 \pm 10,0 \quad 76,2 \pm 8,8 \quad 0,010^{* *}$

$\begin{array}{lllcccc}11 & 91,7 & 1 & 8,3 & 12 & 15,8 & \\ 10 & 66,7 & 5 & 33,3 & 15 & 19,7 & 0,181^{*}\end{array}$

$\begin{array}{llllll}32 & 91,4 & 3 & 8,6 & 35 & 46,1\end{array}$

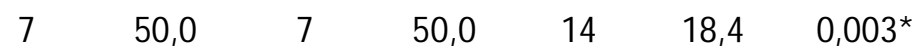

\begin{tabular}{ccccccc}
$26,59 \pm 4,9$ & \multicolumn{2}{c}{$26,19 \pm 7,1$} & & & $0,795^{*}$ \\
7 & 70,0 & 3 & 30,0 & 10 & 13,2 & \\
29 & 85,3 & 5 & 14,7 & 34 & 44,7 & \\
24 & 75,0 & 8 & 25,0 & 32 & 42,1 & $0,448 * * *$
\end{tabular}


Em relação à idade, a média geral da amostra foi de $76,2 \pm 8,8$, sendo que ao separar por grupos, o grupo de idosos frágeis apresentou média de desvio padrão de $81,1 \pm 10$ e o grupo de idosos pré frágeis apresentou $74,9 \pm 8,0$. A diferença entre a média dos grupos foi estatisticamente significativa, sendo $p<0,05(p=0,01)$, o que mostra a incidência de idades mais avançadas no grupo de idosos com fragilidade.

Em relação a faixa etária separada por sexo, os homens apresentaram freqüência de $12 \operatorname{casos}(15,8 \%)$ na faixa de 60 a 79 anos e 15 casos (19,7\%) na faixa 80 anos ou mais. Entre os 12 homens na menor faixa etária, onze estavam no grupo de pré frágeis e um no grupo de frágeis, e dos 15 homens na maior faixa etária, dez estavam no grupo de pré frágeis e 5 no grupo de frágeis. A diferença total de homens entre cada faixa etária não mostrou diferença significativa, $p>0,05$ $(p=1,181)$.

Já em relação às mulheres, a frequência foi de 35 mulheres $(46,1 \%)$ na faixa etária dos 65 aos 79 anos e 14 mulheres $(18,4 \%)$ na faixa etária com 80 anos ou mais. Entre as 35 mulheres da menor faixa etária, 32 estão no grupo dos pré frágeis e três no grupo dos frágeis, e das 14 mulheres na faixa etária maior, sete estão no grupo de pré frágeis e sete no grupo de frágeis, sendo que a diferença entre o total de mulheres e a distribuição por faixa etária foi significativa, $p<0,05(p=0,003)$.

Em relação ao IMC, este foi calculado a média geral de cada grupo de estudo e, separadamente, as freqüências para cada classificação nutricional $(I M C<22$, IMC entre 22 e 27, IMC > 27). A média do grupo pré frágil foi de $26,59 \mathrm{~kg} / \mathrm{m}^{2}$ e do grupo frágil foi de $26,19 \mathrm{~kg} / \mathrm{m}^{2}$, e a diferença não foi significativa, $p>0,05 \quad(p=0,795)$. Quando separado por faixas de IMC,os idosos pré frágeis apresentaram 7 casos (70\%) com IMC $<22 \mathrm{~kg} / \mathrm{m}^{2}, 29$ casos $(85,3 \%)$ de idosos com IMC entre 22 e 27 $\mathrm{kg} / \mathrm{m}^{2}$ e 24 casos $(75 \%)$ de idosos com IMC $>27 \mathrm{~kg} / \mathrm{m}^{2}$. O grupo frágil apresentou uma frequência de 3 casos (30\%) com IMC $<22 \mathrm{~kg} / \mathrm{m}^{2}, 5$ casos $(14,7 \%)$ com IMC entre 22 e $27 \mathrm{~kg} / \mathrm{m}^{2}$ e 8 casos (25\%) com IMC $>27 \mathrm{~kg} / \mathrm{m}^{2}$. A comparação entre cada classificação de IMC e entre cada grupo, não obteve uma diferença significativa, $p$ > $0,05(p=0,448)$.

A tabela 3 também mostra as prevalências de quatro doenças crônicas autorreferidas, diabetes, hipertensão arterial, dislipidemia e osteoporose. Em relação ao diabetes, $22(28,9 \%)$ indivíduos referiram apresentar a doença, sendo que destes, $4(18,2 \%)$ pertenceram ao grupo de idosos frágeis e $18(81,4 \%)$ estavam no grupos de pré frágeis, mas a proporção de idosos diabéticos para não diabéticos nos 
dois grupos foi semelhante e não apresentou diferença significativa, $p>0,05$ $(p=0,767)$.

A hipertensão arterial foi referida por 42 (63,2\%) idosos pesquisados. Destes, $11(22,9 \%)$ pertencem ao grupo de idosos frágeis e $37(77,1 \%)$ pertencem ao grupo de pré frágeis. Assim como no diabetes, a proporção de hipertensos e não hipertensos nos dois grupos foi semelhante e não foi encontrada diferença significativa, $p>0,05(p=0,772)$.

Para a dislipidemia, foi encontrada uma prevalência de $47(61,8 \%)$ entre os participantes do estudo, e dentre estes, 7 (14,9\%) pertencem ao grupo frágeis e 40 $(85,1 \%)$ pertencem ao grupo de pré frágeis. Assim como nas duas doenças anteriores, a dislipidemia apresentou proporção semelhante entre dislipidêmicos e não dislipidêmicos nos dois grupos e não obteve diferença significativa, $p>0,05$ $(p=0,146)$.

Já referente aos casos referidos de osteoporose, estes corresponderam a 30 $(39,5 \%)$ idosos entrevistados. Destes, 10 (33,3\%) pertencem ao grupo de idosos frágeis e $20(66,7 \%)$ ao grupo de idosos não frágeis. Mas, diferentemente das doenças anteriores, no caso da osteoporose, a proporção de doentes e não doentes foi maior no grupo de frágeis em comparação ao grupo de não frágeis, e apresentou diferença estatística significativa, $p>0,05(p=0,045)$.

\subsection{Critérios fenotípicos da Fragilidade}

Como já relatado no capítulo 2, para o diagnóstico de fragilidade, neste estudo foram utilizados os critérios de Fried, 2001. A tabela 5 sumariza as freqüências de cada critério que foi avaliado.

É possível observar que todos os cinco critérios pontuaram para o diagnóstico de fragilidade. A perda de peso não intencional ocorreu em 10 (13,2\%) casos e percebe-se que foi o critério menos pontuado. Destes 10 casos, 5 (50\%) alocaramse no grupo frágeis e 5 (50\%) alocaram-se no grupo de pré frágeis.

A fadiga autorreferida está presente em 18 (23,7\%) dos pesquisados, sendo que $9(50 \%)$ estão no grupo frágeis e 9 (50\%) estão no grupo pré frágeis.

Em relação a velocidade da marcha, 14 (18,4\%) dos idosos pontuaram para este critério, ou seja, tinham a velocidade da marcha maior que o ponto de corte. 
Destes 14 casos, 12 (85,7\%) alocaram-se no grupo de idosos frágeis e apenas 2 $(14,3 \%)$ alocaram-se no grupo de idosos pré frágeis.

Para a força de preensão manual, 74 (97,4\%) dos participantes pontuaram este critério, desta maneira, percebe-se que foi o critério mais pontuado entre os cinco avaliados. Todos os idosos frágeis pontuaram esse critério, $16(21,6 \%)$, e 58 $(78,4 \%)$ dos pré frágeis também pontuaram.

A atividade física, avaliada pelo IPAQ, separou os indivíduos entre os sedentários e os considerados ativos, pela quantidade em minutos de atividade física. Pontuaram esse critério 23 (30,3\%) dos participantes, sendo que destes, 14 $(60,9 \%)$ são do grupo de frágeis e nove $(39,1 \%)$ são do grupo de pré frágeis.

Desta maneira, após contabilização das pontuações, foram classificados 16 (21\%) idosos como frágeis, que pontuaram três ou mais critérios, e 60 (79\%) idosos como pré frágeis, que pontuaram um ou dois critérios. Não houve a observação de idosos hígidos, não frágeis ou pré frágeis, pois todos pontuaram para pelo menos um critério.

Tabela 5. Frequências dos critérios fenotípicos da fragilidade

\begin{tabular}{lcccccc}
\hline Critérios de Fragilidade & Frágeis & $\%$ & Pré Frágeis & $\%$ & Total & $\%$ \\
\hline Perda de Peso & & & & & & \\
Sim & 5 & 50,0 & 5 & 50,0 & 10 & 13,2 \\
Não & 11 & 16,7 & 55 & 83,3 & 66 & 86,8 \\
$\begin{array}{l}\text { Fadiga autorreferida } \\
\text { Sim }\end{array}$ & 9 & 50,0 & 9 & 50,0 & 18 & 23,7 \\
Não & 7 & 12,1 & 51 & 87,9 & 58 & 76,3 \\
Velocidade da Marcha & & & & & & \\
Inadequada & 12 & 85,7 & 2 & 14,3 & 14 & 18,4 \\
$\begin{array}{l}\text { Adequada } \\
\text { Preesão Manual }\end{array}$ & 4 & 6,5 & 58 & 93,5 & 62 & 81,6 \\
Inadequada & 16 & 21,6 & 58 & 78,4 & 74 & 97,4 \\
Adequada & 0 & 0,0 & 2 & 100,0 & 2 & 2,6 \\
Atividade Física & & & & & & \\
Sedentário & 14 & 60,9 & 9 & 39,1 & 23 & 30,3 \\
Regular & 2 & 3,8 & 51 & 96,2 & 53 & 69,7 \\
\hline
\end{tabular}




\subsection{Ingestão de nutrientes e Fragilidade}

Para a análise da ingestão de nutrientes foi utilizado inquérito alimentar do tipo recordatório de 24 horas. Foram coletados dois inquéritos em dias habituais da semana. O cálculo foi realizado com auxílio de um softwarede apoio ao nutricionista e os valores de ingestão foram expostos em média e DP de cada grupo, como apresenta a tabela 6 . Além da avaliação das médias de ingestão de nutrientes por cada grupo, também foi realizada análise de adequação nutricional em relação às DRl's para cada grupo e a partir do número de indivíduos com ingestão adequada ou não, foram testadas as chances bilateral (de fragilidade para ingestão ou ingestão para a fragilidade) com o cálculo do Odds ratio, como exposto na tabela 7.

Em relação aos macronutrientes e fibras, percebe-se pequenas diferenças em relação às médias de ingestão de cada grupo, mas sem diferenças estatisticamente significativas. Pode-se observar que a média de ingestão calórica e de carboidratos é menor no grupo de frágeis, $1418,1 \pm 434,9$ e $1356,9 \pm 334,5$ de calorias, e $189,2 \pm 48,6$ e $175,3 \pm 36,9$ de carboidratos, no grupo pré frágil e frágil, respectivamente, e que de proteínas e gorduras totais é menor no grupo de pré frágeis, $58,7 \pm 20,1$ e $61 \pm 24$ de proteínas, e $46,7 \pm 17,1$ e $48,1 \pm 19,2$ de gorduras totais, no grupo pré frágil e frágil, respectivamente. Referenteàs gorduras totais, percebe-se a maior ingestão pelo grupo de frágeis, no entanto, este grupo obteve uma média de ingestão inferior em relação ao colesterol e ácido graxo poliinsaturado, do tipo ômega seis. Já em relação ao ômega três e fibras, as médias foram muito semelhantes, como pode-se observar na tabela 6 .

No tocante ao consumo de micronutrientes, os sais minerais apresentaram médias de ingestão bem próximas entre os grupos. Pode-se observar dois minerais que apresentaram uma média de ingestão um pouco inferior pelo grupo de pré

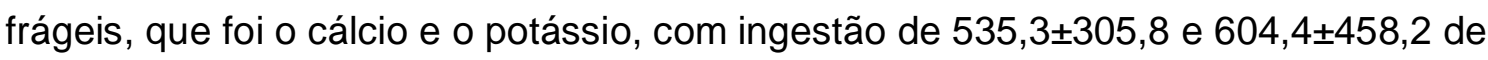

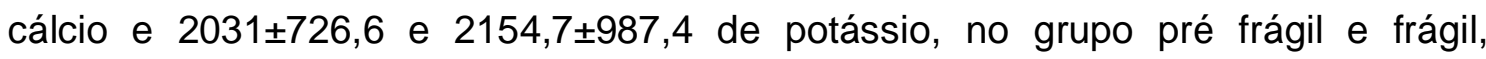
respectivamente. No entanto, nenhuma comparação entre médias apresentaram diferenças estatisticamente significativas.

Ainda referente aos micronutrientes, as vitaminas também apresentaram médias de consumo muito semelhantes entre os grupos. A vitamina $A$, apresentou uma média geral de consumo inferiorpelogrupode frágeis, sendo $411,2 \pm 319,4$ e 
Tabela 6. Média e DP da ingestão de nutrientes por cada grupo

\begin{tabular}{|c|c|c|c|}
\hline \multirow[t]{2}{*}{ Nutrientes } & \multirow{2}{*}{$\begin{array}{l}\text { Pré Frágil } \\
\text { Média (DP) }\end{array}$} & \multirow{2}{*}{$\begin{array}{c}\text { Frágil } \\
\text { Média (DP) } \\
\end{array}$} & \multirow[b]{2}{*}{ Valor-P } \\
\hline & & & \\
\hline Energia (kcal) & $1418,1 \pm 434,9$ & $1356,9 \pm 334,5$ & $0,863^{*}$ \\
\hline \multicolumn{4}{|l|}{ Macronutrientes } \\
\hline Carboidratos (g) & $189,2 \pm 48,6$ & $175,3 \pm 36,9$ & $0,311^{*}$ \\
\hline Proteínas (g) & $58,7 \pm 20,1$ & $61 \pm 24$ & $0,903^{*}$ \\
\hline Gorduras Totais (g) & $46,7 \pm 17,1$ & $48,1 \pm 19,4$ & $0,913^{*}$ \\
\hline Colesterol (mg) & $182,2 \pm 153,3$ & $156 \pm 99,1$ & $0,669^{*}$ \\
\hline \multicolumn{4}{|c|}{ Gorduras Poliinsaturadas } \\
\hline Ômega 3 (mg) & $1,3 \pm 0,5$ & $1,2 \pm 0,3$ & $0,332^{*}$ \\
\hline Ômega 6 (mg) & $10,1 \pm 4,2$ & $8,6 \pm 2,5$ & $0,223^{*}$ \\
\hline Fibras (g) & $17,2 \pm 6,5$ & $17,3 \pm 7,2$ & $0,893^{*}$ \\
\hline \multicolumn{4}{|l|}{ Micronutrientes } \\
\hline \multicolumn{4}{|l|}{ Sais Minerais } \\
\hline Cálcio (mg) & $535,3 \pm 305,8$ & $604,4 \pm 458,2$ & $0,873^{*}$ \\
\hline Ferro (mg) & $10,1 \pm 3,4$ & $9,6 \pm 2,9$ & $0,624^{\star *}$ \\
\hline Fósforo (mg) & $903,9 \pm 381,7$ & $907,4 \pm 453,9$ & $0,660^{*}$ \\
\hline Potássio (mg) & $2031 \pm 726,6$ & $2154,7 \pm 987,4$ & $0,984^{*}$ \\
\hline Zinco (mg) & $7,3 \pm 3$ & $7,5 \pm 2,8$ & $0,780^{* *}$ \\
\hline Magnésio (mg) & $230,5 \pm 79,9$ & $217,2 \pm 82,4$ & $0,558^{*}$ \\
\hline M anganês (mg) & $1,9 \pm 1,1$ & $1,8 \pm 0,9$ & $0,918^{*}$ \\
\hline \multicolumn{4}{|l|}{ Vitaminas } \\
\hline Vitamina A (RE) & $411,2 \pm 319,4$ & $374,5 \pm 184,3$ & $0,688^{*}$ \\
\hline Vitamina E (mg) & $5,5 \pm 1,8$ & $5,6 \pm 1,4$ & $0,924^{* *}$ \\
\hline Vitamina B1 (mg) & $1,3 \pm 0,5$ & $1,2 \pm 0,5$ & $0,352^{*}$ \\
\hline Vitamina B2 (mg) & $1,3 \pm 0,5$ & $1,2 \pm 0,6$ & $0,622^{\star *}$ \\
\hline Vitamina B3 (mg) & $13,6 \pm 5,9$ & $15,3 \pm 6,7$ & $0,302^{*}$ \\
\hline Vitamina B5 (mg) & $3,4 \pm 1,3$ & $3,9 \pm 1,7$ & $0,414^{*}$ \\
\hline Vitamina B6 (mg) & $1,2 \pm 0,5$ & $1,3 \pm 0,7$ & $0,878^{*}$ \\
\hline Vitamina B9 (mcg) & $248,3 \pm 118,3$ & $251,2 \pm 83,4$ & $0,927^{* *}$ \\
\hline Vitamina B12 (mcg) & $2,6 \pm 1,5$ & $3 \pm 1,5$ & $0,185^{*}$ \\
\hline Vitamina C(mg) & $61,5 \pm 59,1$ & $139,8 \pm 101,5$ & $0,001^{* * *}$ \\
\hline
\end{tabular}

$374,5 \pm 184,3$ no grupo pré frágil e frágil, respectivamente, mas sem apresentar diferença estatística significativa. Já em relação a vitamina $C$, a ingestão média foi 
de $61,5 \pm 59,1$ no grupo pré frágil e $139,8 \pm 101,5$ no grupo frágil, sendo que esta diferença foi significativa, $p<0,05(p=0,001)$.

A tabela 7, trás a adequação nutricional em relação às recomendações atuais para cada nutriente. Além da adequação, trás também a razão de chances para cada inadequação, comparado entre um grupo exposto e outro não exposto, ou seja, entre os idosos pré frágeis e frágeis, os expostos foram o que apresentaram ingestão inadequada e os não expostos foram considerados aqueles com ingestão de nutrientes considerada adequada. O objetivo desta medida de associação foi verificar quantas vezes mais chances os idosos com a inadequação nutricional tinham em ser frágeis. No entanto, o odds ratio (OR) também permite a avaliação inversa, ou seja, quantas vezes mais chances o idoso frágil tem em apresentar uma inadequação nutricional. Para as duas interpretações citadas, o valor de OR precisa estar acima de 1, e quando o resultado se mostra abaixo de 1, sugere-se que no caso a inadequação exerce maior chance de proteção e não de risco. Porém, em ambos os casos, o valor de OR foi acompanhando pelo seu intervalo de confiança e a inadequação foi testada por modelo estatístico, a fim de verificar se os valores de OR apresentam significância.

Para os macronutrientes, como as recomendações são individuais, foram calculadas adequações em relação a recomendação de distribuição, onde foi considerado adequada a distribuição com 55\% de carboidratos, 20\% de proteínas e $25 \%$ de gorduras. Já os demais nutrientes, as adequações foram calculadas com valores fixos para cada recomendação das DRl's.

A adequação de carboidratos para os dois grupos foi muito próxima à recomendação de $55 \%$, sendo $56 \%$ dos pré frágeis e $52 \%$ dos frágeis. No teste de chances, o OR foi de 1,13, bem próximo a um, referindo 1,13 mais chances do grupo frágil apresentar inadequação de carboidratos, porém com intervalo de confiança (IC) e valor de p com diferença não significativa. A proporção de ingestão protéica e de gorduras seguiu a mesma distribuição de proporções muito próximas à recomendação de $20 \%$ para proteínas e 25\% para gorduras. A adequação protéica foi de $17 \%$ no grupo pré frágil e $18 \%$ no grupo frágil, e a adequação de gorduras foi de $30 \%$ no grupo de pré frágeis e $32 \%$ no grupo de frágeis. Também para o teste de chances, ambos apresentaram valores próximo de um, 1,44 e 1,21 para proteínas e gorduras, respectivamente, e o IC e valor de $p$ não demonstraram diferenças significativas. 
Tabela 7. Adequação da ingestão de nutrientes em relação às DRl's e teste de chances

\begin{tabular}{|c|c|c|c|c|c|c|}
\hline \multirow[t]{2}{*}{ Nutrientes } & \multirow{2}{*}{$\begin{array}{c}\text { Adequação (\%) } \\
\text { Pré Frágil } \\
\end{array}$} & \multirow{2}{*}{$\begin{array}{c}\text { Adequação (\%) } \\
\text { Frágil } \\
\end{array}$} & \multirow{2}{*}{$\begin{array}{c}\text { DRI's } \\
\text { (EAR/AI/RDA) }\end{array}$} & \multirow[t]{2}{*}{ OR } & \multirow[t]{2}{*}{ IC95\% } & \multirow[t]{2}{*}{ Valor-P* } \\
\hline & & & & & & \\
\hline \multicolumn{7}{|l|}{ Macronutrientes } \\
\hline Carboidratos (\%) & 56 & 52 & 55 & 1,13 & $(0,37 ; 3,41)$ & 1,00 \\
\hline Proteínas (\%) & 17 & 18 & 20 & 1,44 & $(0,36 ; 5,77)$ & 0,75 \\
\hline Gorduras Totais (\%) & 30 & 32 & 25 & 1,21 & $(0,33 ; 4,37)$ & 0,75 \\
\hline Colesterol (mg) & 61 & 52 & 300 & 1,08 & $(0,2 ; 5,79)$ & 1,00 \\
\hline \multicolumn{7}{|l|}{ Poliinsaturadas } \\
\hline Ômega 3 (g) & 81 & 75 & 1,6 & 1,58 & $(0,4 ; 6,26)$ & 0,75 \\
\hline Ômega 6 (g) & 72 & 61 & 14 & 3,00 & $(0,35 ; 25,37)$ & 0,44 \\
\hline Fibras (g) & 57 & 58 & 30 & 0,52 & $(0,04 ; 6,09)$ & 0,51 \\
\hline \multicolumn{7}{|l|}{ Micronutrientes } \\
\hline \multicolumn{7}{|l|}{ Sais Minerais } \\
\hline Cálcio (mg) & 45 & 50 & 1200 & 0,23 & $(0,04 ; 1,26)$ & 0,10 \\
\hline Ferro (mg) & 168 & 160 & 6 & 2,00 & $(0,33 ; 12,05)$ & 0,60 \\
\hline Fósforo (mg) & 156 & 156 & 580 & 1,67 & $(0,45 ; 6,24)$ & 0,47 \\
\hline Potássio (mg) & 43 & 46 & 4700 & 0,08 & $(0,003 ; 2,20)$ & 0,21 \\
\hline Znco (mg) & 78 & 80 & 9,4 & 0,32 & $(0,1 ; 1,04)$ & 1,00 \\
\hline M agnésio (mg) & 66 & 62 & 350 & 0,37 & $(0,06 ; 2,42)$ & 0,28 \\
\hline M anganês (mg) & 83 & 78 & 2,3 & 1,58 & $(0,4 ; 6,26)$ & 0,74 \\
\hline \multicolumn{7}{|l|}{ Vitaminas } \\
\hline Vitamina A (RE) & 66 & 60 & 625 & 0,01 & $(0,0007 ; 0,2)$ & 0,0001 \\
\hline Vitamina $\mathrm{E}$ (mg) & 46 & 47 & 12 & 0,83 & $(0,03 ; 21,4)$ & 1,00 \\
\hline Vitamina B1 (mg) & 130 & 120 & 1 & 1,15 & $(0,34 ; 3,80)$ & 1,00 \\
\hline Vitamina B2 (mg) & 118 & 109 & 1,1 & 2,03 & $(0,65 ; 6,32)$ & 0,26 \\
\hline Vitamina B3 (mg) & 113 & 128 & 12 & 0,84 & $(0,27 ; 2,61)$ & 1,00 \\
\hline Vitamina B5 (mg) & 68 & 78 & 5 & 0,27 & $(0,06 ; 1,17)$ & 0,08 \\
\hline Vitamina B6 (mg) & 86 & 93 & 1,4 & 1,39 & $(0,39 ; 4,88)$ & 0,76 \\
\hline Vitamina B9 (mcg) & 78 & 79 & 320 & 1,19 & $(0,29 ; 4,85)$ & 1,00 \\
\hline Vitamina B12 (mcg) & 130 & 150 & 2 & 0,46 & $(0,13 ; 1,61)$ & 0,26 \\
\hline Vitamina C & 82 & 186 & 75 & 0,09 & $(0,02 ; 0,36)$ & 0,0003 \\
\hline
\end{tabular}

*Teste exato de Fisher

Em relação à adequação de gorduras, foi separado os valores de colesterol e ácidos graxos poliinsaturados ômega 3 e 6 . Para o colesterol, o grupo frágil apresenta aparentemente uma média geral de ingestão menor e consequentemente uma adequação de $52 \%$. Já o grupo de pré frágeis apresentou um consumo médio maior de colesterol e uma adequação de $61 \%$. No entanto, o teste de chances é 
praticamente um, no caso de OR reflete igualdade, e seu IC e valor de $p$ indicaram diferença não significativa. Já em relação ao ômega 3 e 6, ainda que as diferenças não foram significativas pelo IC e valor p, o OR mostra uma chance de 1,5 e 3 vezes maior do idosos frágeis apresentarem inadequação de ômega 3 e 6, respectivamente em comparação aos idosos pré frágeis. A adequação de ômega 3 foi de $81 \%$ nos grupo de pré frágeis e $75 \%$ no grupo de frágeis e de ômega 6 foi de $72 \%$ nos pré frágeis e $61 \%$ nos frágeis.

A ingestão de fibras mostrou uma adequação pelos dois grupos menor que a recomendação e muito próxima entre eles, sendo 57\% no grupo pré frágil e $58 \%$ no grupo frágil. Neste caso, o teste de chances mostrou efeito contrário, onde aparentemente, devido a distribuição com maior consumo de fibras pelo grupo frágil, o OR foi de 0,52 e reflete maior chances de ser frágil com a ingestão adequada de fibras. Porém, os valores de IC e p não mostraram diferenças significativas desse efeito.

Referente aos sais minerais, o ferro e o fósforo apresentaram adequações superiores a $100 \%$, sendo $168 \%$ no grupo pré frágeis e $160 \%$ no grupo frágeis para o ferro, e 156\% em ambos os grupos para o fósforo. Já o manganês, apresentou adequação de $83 \%$ para os pré frágeis e $78 \%$ para os frágeis. Estes três nutrientes, no teste de chances, mostraram um OR de 2; 1,67 e 1,58, respectivamente, e sugerem maiores chances de inadequação nutricional desses nutrientes pelos idosos frágeis. No entanto, nenhuma diferença entre os grupo para os três nutrientes foi significativa.

Em relação ao cálcio, potássio, zinco e magnésio, seus valores de OR foram menor que um, sendo 0,23; 0,08; 0,32 e 0,37, o que sugere a situação reversa, neste caso, a ingestão inadequada parece associar-se aos pré frágeis e não aos frágeis. A adequação desses minerais foi de 45\%, 43\%, 78\% e 66\% para cálcio, potássio, zinco e magnésio, respectivamente, no grupo de pré frágeis e $50 \%, 46 \%$, $80 \%$ e $62 \%$ para cálcio, potássio, zinco e magnésio, respectivamente, no grupo de frágeis. Nenhuma diferença calculada pelo IC e valor de $p$ foi considerada significativa.

O consumo de vitaminas ocorreu de maneira similar aos minerais, na maioria dos casos as médias de ingestão entre os grupos foram bem próximas. A vitamina $E$ apresentou adequação de $46 \%$ no grupo de pré frágeis e $47 \%$ nos frágeis. O valor de OR foi de 0,83 , o que sugere maiores chances de serem frágeis os idosos com 
consumo adequado de vitamina E. As vitaminas B3, B5 e B12, apresentaram distribuição similar, onde o valor de $\mathrm{OR}$ foi de 0,$84 ; 0,27$ e 0,46 , respectivamente, sugerindo que as maiores chances de inadequação dessas vitaminas estão no grupo de pré frágeis e não frágeis. A adequação nutricional foi de $113 \%, 68 \%$ e $130 \%$ para $B 3$, B5 e B12, respectivamente, para o grupo de pré frágeis e $128 \%, 78 \%$ e $150 \%$ para B3, B5 e B12, respectivamente, para o grupo de frágeis. O IC e valor de $p$ não mostraram diferenças significativas para essas vitaminas.

As vitaminas B1, B2, B6 e B9 apresentaram valores de OR de 1,15; 2,03; 1,39 e 1,19 respectivamente. Valores bem próximo a um, que remete igualdade de chances, com exceção da vitamina B2 que apresenta cerca de duas vezes mais chances de inadequação pelo grupo de pré frágeis. As proporções de inadequação foram de 130; 118; 86 e 78\% para B1, B2, B6 e B9, respectivamente no grupo de pré frágeis e de 120; 109; 93 e 79\% para B1, B2, B6 e B9, respectivamente no grupo de frágeis. Nenhuma diferença foi significativa de acordo com IC e valor de $p$.

Já no caso da vitamina $A$ e vitamina $C$, o valor de $O R$ foi de 0,01 e 0,09, respectivamente, com IC que mostrou diferença significativa entre as taxas de chances. No caso das duas vitaminas, o valor inferior a um também remete maiores chances de inadequações no grupo de pré frágeis em relação aos frágeis. A adequação foi de 66 e $60 \%$ de vitamina A para grupo pré frágil e frágil, respectivamente e de 82 e 186\% para a vitamina C para grupo pré frágil e frágil, respectivamente, sendo que $o$ valor de $p$ nestes casos apontou diferenças significativas, $p<0,05$ ( $p=0,0001$ para vitamina $A$ e $p=0,0003$ para vitamina $C)$.

Outro ponto importante a ser observado, é que em relação à adequação nutricional quanto às DRl's, independente das comparações entre os grupos frágeis e pré frágeis, dos três macronutrientes avaliados (carboidratos, proteínas e gorduras), dois apresentam adequação pelos grupos, sendo que as gorduras totais estão superior nos dois grupos. Dos 16 micronutrientes avaliados, somente seis deles apresentam adequação (ferro, fósforo, vitaminas B1, B2, B3, B12) e os demais onze apresentam inadequação, nos dois grupos. Referente às fibras, estas apresentam inadequação nos dois grupos. 


\section{Capítulo 4}

\section{Discussão}

No estudo de Augusti, Falsarella e Coimbra (2017), sobre a prevalência da SF na atenção primária à saúde, foi trabalhado com uma amostra com 39,7\% de homens e $60,3 \%$ de mulheres, valores muito próximos trabalhados neste estudo, que foi de $35,5 \%$ de homens e $60,3 \%$ de mulheres. No estudo de Mello et al., (2017), também estudaram a fragilidade em idosos da comunidade, e trabalharam com uma amostra de $32,1 \%$ de homens e $67,9 \%$ de mulheres. Percebe-se desta forma, que a proporção entre homens e mulheres tende a ser semelhantes nos estudos sobre fragilidade na comunidade.

Augusti, Falsarella e Coimbra (2017) encontraram uma média de idade de $72 \pm 5,71$ anos dos participantes, resultado próximo ao trabalhado neste estudo, que foi de 76,2 $\pm 8,8$ anos. Mello et al., (2017) encontraram média de idade em seu grupo de $70,2 \pm 7,4$ anos. No entanto, quando separada a amostra por faixa etária, Mello et al., trabalharam com uma prevalência de $86,9 \%$ de idosos de 60 a 79 anos e $13,1 \%$ de idosos com 80 anos ou mais. Neste estudo, a prevalência de idosos mais velhos foi maior, sendo $61,9 \%$ na faixa etária dos 60 aos 79 anos e $38,1 \%$ na faixa etária de 80 anos ou mais, com distribuição semelhante entre homens e mulheres. Uma hipótese para a diferença neste caso é que o trabalho de Mello et al., estudaram uma população de capital, residente em área de favela, mais potencialmente ativa, em contra partida, este estudo pesquisou uma comunidade sem características de favela, coberta por Estratégia de Saúde da Família e de uma cidade do interior. Estudo ecológico realizado por Alves et al, (2016) concluiu que favelas apresentam menor prevalência de idosos que outros bairros, inclusive, neste estudo, foi avaliada a mesma região que foi realizada o estudo de Mello et al, (2017).

O IMC avaliação conforme classificação para idosos, classificou três grupos, Baixo Peso, Eutróficos e Excesso de Peso. Neste estudo, maior parte dos idosos foram classificados como Eutróficos, $34(44,7 \%)$ dos casos, seguido por $32(42,1)$ de Excesso de Peso e $10(13,2 \%)$ de Baixo Peso. Após a transição epidemiológica e 
nutricional da população, hoje as doenças crônicas, causam danos significativos a saúde. Não diferente na população idosa, os casos de baixo peso e desnutrição hoje, são menores que os casos de excesso de peso (PEREIRA, SPYRIDES \& ANDRADE, 2016). Percebe-se com esta prevalência, que os critérios de fragilidade têm convivido junto com o excesso de peso, o que pode configurar, muitas vezes, a obesidade sarcopênica, onde mesmo sem estar com baixo peso o idosos ainda apresentam redução de massa muscular, fraqueza, fadiga, baixa atividade física, conseqüente marcha reduzido, entre uma série de outros fatores que contribuem para o fenótipo da fragilidade. Em trabalho de Neto et al., (2012), com idosos sarcopênicos e obesos sarcopênicos, foi encontrado associação positiva entre as duas condições e a força muscular dos idosos, o que mostrou que a obesidade prejudica a força e qualidade de vida da mesma maneira que idosos sarcopênicos não obesos. No trabalho de Melo et al., (2017) os resultados demonstraram que com a evolução do idoso hígido para pré frágil e posteriormente frágil, também ocorre um aumento do IMC de baixo peso para excesso de peso, diretamente proporcional, o que reforça a coexistência de excesso de peso e redução de massa muscular.

As DCNT ocupam lugar entre as principais causas de morte em todo o mundo, que pode variar de $37 \%$ das causas em países em desenvolvimento e chegando a 88\% em países desenvolvidos (OMS, 2015). No Brasil, em 2011, foi implantado o plano de ações estratégicas para o enfrentamento de doenças crônicas não transmissíveis, a fim de estipular metas e ações para os próximos dez anos, com objetivo de reduzir e preparar o país para o enfrentamento das DCNT (MALTA, MORAIS NETO \& SILVA JÚNIOR, 2011). Desta maneira, percebe-se a importância da investigação em torno das DCNT e suas associações com outras variáveis de interesse.

Neste trabalho foi questionada sobre a presença de quatro DCNT muito prevalentes entre a população idosa. A maior prevalência na amostra foi de hipertensão arterial, com $48(63,2 \%)$ casos, seguido por dislipidemias, com 47 $(61,8 \%)$ de casos, osteoporose, com 30 (39,5\%) de casos e diabetes, com 22 $(28,9 \%)$ dos casos. No trabalho de Santos et al., (2015), a prevalência de hipertensão arterial e de diabetes na amostra estudada foi de 64,7 e 15,1\% respectivamente, o que mostra valores de hipertensão arterial semelhantes, e valores maiores de diabetes neste estudo. Outra pesquisa com idosos frágeis na comunidade encontrou prevalências de $70,4 \%$ de hipertensão arterial, $18,4 \%$ de 
osteoporose e 34\% de diabetes (AUGUSTI, FALSARELLA E COIMBRA, 2017). Mais uma vez, valores muito semelhantes para a hipertensão arterial, e desta vez, prevalência muito semelhante também de diabetes, pois a população de estudo também se trata de uma comunidade com abrangência de Estratégia de Saúde da Família e de um município do interior de São Paulo. No entanto, a prevalência de osteoporose neste estudo foi maior que no trabalho citado, o que pode estar associado ao fato de que a população deste estudo apresentou média de idade um pouco mais elevada que o trabalho mencionado acima. Entre as quatro DCNT questionadas, a osteoporose foi a única que mostrou uma diferença significativa entre as proporções de casos entre os frágeis e pré frágeis, o que sugere que a saúde óssea prejudicada pode agir como fator de risco para a fragilidade. Um estudo realizado com 900 idosos do banco de dados do estudo FIBRA encontrou prevalência de $26,4 \%$ de casos de osteoporose entre a amostra (PEREIRA, BORIM \& NERI, 2017).

Ponto relevante neste estudo está relacionado aos critérios de fragilidade. Foram avaliados cinco critérios fenotípicos e sendo que o preenchimento de três deles foi suficiente para o diagnóstico de fragilidade. O fenótipo da fragilidade, definido por Fried et al., (2001), objetivou identificar um grupo de idosos que apresentam risco para sua saúde, com desfechos ligados à fragilidade. A perda de peso não intencional foi o item com menor incidência de ocorrência neste estudo. Fato que pode estar associado com a elevada prevalência de excesso de peso atualmente e/ou também,ao fato da possibilidade do idoso se enganar ao tentar referir seu peso de 12 meses atrás. Em estudo realizado na atenção primária sobre prevalência de fragilidade, a perda de peso não intencional ocorreu em $21,2 \%$ da amostra, valor razoavelmente maior que o encontrado neste trabalho, de 13,2\%. Este mesmo estudo obtevefreqüênciasemelhantede fadiga autorreferida $(28,1 \%)$, freqüência inferior de inatividade física (19,6\%) e preensão manual (19,6\%); e valores superiores de velocidade da marcha (86,6\%), quando comparados a este estudo (AUGUSTI, FALSARELLA E COIMBRA, 2017). Amaral et al., (2013), ao investigarem a prevalência de fragilidade em idosos da comunidade, encontraram freqüências de $38,7 \%$ de fadiga autorreferida, $30,7 \%$ de perda de peso não intencional, 26,7\% de baixo nível de atividade física, 22,3\% de redução da força muscular e $19 \%$ de redução da velocidade da marcha. Neste caso, a fadiga 
autorreferida e a baixa atividade física se mostraram semelhantes às freqüências encontradas neste estudo.

A força de preensão manual neste trabalho foi um indicador relevante para a formação dos grupos, pois foi o maior responsável por não haverem idosos hígidos na amostra, ao considerar que somente dois indivíduos $(2,6 \%)$ apresentaram adequação neste critério. De fato, durante a coleta, pôde-se observar que os idosos apresentaram muita dificuldade em conseguir valores mais elevados que $5 \mathrm{~kg} / \mathrm{f}$ na preensão manual. Muitas foram as queixas, mas principalmente, sintomas de artrite reumatóide foram relatados, e associados pelo idoso com a falta de força de preensão. Outra discussão muito importe, refere-se aos pontos de corte para este item, cujos valores de Fried et al., (2001) são provenientes de uma amostra americana, com composição corporal diferente da população idosa brasileira. Nenhum trabalho que mostrasse igual prevalência elevada neste critério foi encontrado na literatura. No entanto, mesmo ao analisar outros trabalhos nacionais, que utilizaram pontos de corte com base em outras referências, os idosos deste estudo não apresentariam uma adequação tão menor que a encontrada, pois mesmo as referencias com pontos de corte mais baixos, ainda eram superiores às medidas obtidas pela amostra deste estudo.

No tocanteà ingestão de nutrientes, foram realizadas três análises. A primeira foi a comparação entre as médias dos grupos, onde apenas a vitamina $C$ mostrou diferença significativa. No entanto, a média de ingestão de nutrientes por si só, não remete à adequação nutricional dos mesmos, mais somente se existe diferença entre o grupo que ingeriu mais e o que ingeriu menos. Desta maneira, a análise de adequação objetivou ilustrar não só a quantidade ingerida, mas o quanto esta quantidade esta adequada em relação às DRl's. Ainda, através da análise de contingência, por delineamento de um modelo não pareado caso-controle, onde se partiu do diagnóstico de frágeis e não frágeis (pré frágeis) e expostos (com inadequação nutricional) e não expostos (com adequação nutricional), objetivou-se testar o número de chances em ser frágil e apresentar alguma inadequação nutricional, ou o contrário. Nestas duas análises, a vitamina $A$ e a vitamina $C$ mostraram diferenças significativas de adequação entre os grupos e no teste de chances. Não foram encontrados estudos brasileiros que quantificaram a ingestão de nutrientes por idosos frágeis e compararam às DRl's. Alguns trabalhos 
internacionais utilizaram inquéritos alimentares e quantificaram a ingestão de alguns nutrientes, e serão referidos nesta parte da discussão.

Zainuddin et al., (2017) em um trabalho que avaliou a associação entre insegurança alimentar e fragilidade, comparou as médias de ingestão de energia, carboidratos, proteínas, gorduras e cálcio, e não encontrou diferenças significativas entre os idosos frágeis e não frágeis.

Kobayashi et al., (2014), por meio de um estudo transversal, encontrou que a menor ingestão pelos idosos frágeis das vitaminas A, D, E, C, B6, B9 e B12 e dos macronutrientes carboidratos, gorduras totais e proteínas, estava associada a menor prevalência de fragilidade. Neste estudo, os idosos frágeis também mostraram ingestão e inadequação nutricional menor para as vitamina $A$ e B12, sendo que somente a vitamina $A$ mostrou diferença significativa na análise de contingência para a adequação nutricional. A ingestão de carboidratos também foi menor pelo grupo de frágeis, mas sem diferença significativa. A vitamina $C$ mostrou o que chamamos de causalidade reversa, ou seja, tanto na comparação entre médias, quanto para a análise de adequação, sua diferença foi significativa entre os grupos, no entanto, com sua quantidade menor de ingestão e inadequação, ocasionada no grupo de pré frágeis, e não nos frágeis.

A ingestão calórica e de carboidratos foi maior pelo grupo de idosos pré frágeis, enquanto que as proteínas e gorduras totais mostraram valores semelhantes. A hipótese para essa ocorrência seria que o idoso frágil busca por alimentos menos consistentes e de fácil preparo, e acaba por recorrer a alimentos menos calóricos e mais macios, como frutas, por exemplo, que pode elevar a ingestão de vitamina $\mathrm{C}$, como mostrado pela causalidade reversa, e também, pelo discreto consumo mais elevado de potássio pelo grupo frágil, mineral muito associado como marcador de consumo de frutas.

Já no caso do trabalho de Smit et. al., (2013), que realizaram um estudo transversal utilizando uma base de dados populacionais americana, a Third National Health and Nutrition Examination Survey (NHANES III), e avaliaram a ingestão alimentar de 4731 idosos com 60 anos ou mais através do recordatório de 24 horas. Encontraram que o consumo de energia era mais elevado nos idosos não frágeis. Os idosos pré-frágeis apresentaram um consumo intermediário e os idosos frágeis o menor consumo. 
Estudo transversal e multicêntrico inédito realizado no Japão foi além da ingestão proteica e desfecho de fragilidade, avaliou também os tipos de proteínas (animal ou vegetal), bem como a composição de aminoácidos e a relação com a fragilidade. O trabalho estudou 2108 idosos com 65 anos ou mais, em 35 províncias do Japão. Os idosos participantes eram conhecidos de estudantes de nutrição de 85 instituições de ensino espalhadas pelas diferentes províncias do país. A ingestão alimentar foi avaliada por um questionário de história alimentar auto-aplicável. A ingestão proteica > 69,8 g/dia mostrou relação positiva com a condição de não frágil, independentemente da origem (animal ou vegetal) e da composição de aminoácidos essenciais. No presente estudo, nenhum dos grupos apresentou ingestão protéica maior ou igual á quantidade referida pelos pesquisadores, hipótese que também sugere relação com as escolhas alimentares dos idosos, que priorizam menos alimentos consistentes, como carnes, ou com mais dificuldades de preparo, como leguminosas (KOBAYASHI et al., 2014).

Em um coorte prospectivo americano que estudou 5.925 homens, com 65 anos ou mais, cadastrados no Osteoporotic Fractures in Men (MrOS) study, avaliou a ingestão alimentar de macronutrientes e fibras, bem como a qualidade global da dieta. Nesta pesquisa acima, não foram encontradas associações significativas entre ingestão de macronutrientes (carboidratos, proteínas e gorduras) e fibras com as condições de fragilidade, assim como o presente estudo também não encontrou associação significativas para macronutrientes e fibras (SHIKANY et al., 2014).

Bollwein et. al., (2013), em um trabalho transversal com 194 idosos de 75 anos ou mais, na Alemanha, objetivou não só estudar a ingestão protéica como fator protetor para a fragilização em idosos, mas analisou também a distribuição das proteínas ingeridas ao longo do dia (manhã, tarde e noite), com a finalidade de melhor entender o anabolismo proteico dentro do período. A ingestão alimentar foi avaliada por um questionário de frequência alimentar. Nesse trabalho não houve diferenças significativas no consumo de energia e proteínas entre os grupos estudados (frágeis, pré-frágeis e não frágeis), no entanto, os idosos frágeis consumiram significantemente menos proteínas na parte da manhã em comparação aos idosos pré-frágeis e não frágeis.

Em tese de doutorado Mello et. al., (2014), em estudo transversal com 137 idosos, avaliaram a ingestão dietética de diferentes grupos alimentares e sua relação com o desfecho de fragilidade, no entanto, não estudaram os constituintes 
nutricionais individualmente desses grupos alimentares. Grupos alimentares que apresentam em sua composição maior teor de macronutrientes, como cereais, feijões, laticínios, carnes e ricos em açúcares e gorduras foram estudados. Desses grupos, os feijões apresentaram um fator protetor para o desenvolvimento de fragilidade.

A relação da ingestão de micronutrientes com a Síndrome da Fragilidade está menos estabelecida em comparação às proteínas e energia. Poucos estudos avaliam a ingestão de micronutrientes, talvez pela maior dificuldade de quantificar esses elementos ou escassez dessas informações em tabelas de composição, como por exemplo, a vitamina $\mathrm{D}$, que não está disponível na maioria das tabelas de composição de alimentos.

No estudo In CHIANTI, com idosos italianos, verificou que a baixa ingestão das de algumas vitaminas associa-se significativamente com a condição de fragilidade. Para a vitamina $D$, a exposição foi avaliada em uma ingestão de $<1,4$ ug para homens e $<1,1$ ug para mulheres. Para a vitamina $E$, a ingestão de $<5,1 \mathrm{mg}$ para homens e $<4,5 \mathrm{mg}$ para mulheres, expôs à síndrome. Já a vitamina $\mathrm{C}$ se tornou uma exposição de risco nos valores de <75,2 mg para homens e <73,6 mg para mulheres. Em relação ao ácido fólico (Vitamina B9), a ingestão de <214 mg para homens e $<184 \mathrm{mg}$ para as mulheres mostrou-se como risco para a fragilidade. Todas essas quantidades caracterizaram o quintil mais baixo de ingestão. Neste trabalho, a ingestão de vitaminas E e B9 foram superior ao limite de exposição citado pelos autores, mas a vitamina $\mathrm{C}$ esteve abaixo de $75 \mathrm{mg}$ no grupo de idosos pré frágeis, o que remete a outro motivo para a causalidade reversa, ou seja, para que pudesse exercer efeito como proteção, primeiramente a ingestão deveria ser adequada pelo grupo que ainda não se tornou frágil (BARTALI et al., 2006).

Mello et al, (2017), avaliaram o consumo alimentar de idosos frágeis e pré frágeis, por meio de um questionário de freqüência alimentar e observaram maior consumo de cereais, alimentos fonte de carboidratos, pelos idosos frágeis, e maior consumo de feijão, frutas, laticínios e alimentos ricos em açúcares e gorduras pelos idosos pré frágeis. A ingestão de verduras e legumes e carnes foi semelhante entre os idosos frágeis e pré frágeis. Os pesquisadores também avaliaram a ingestão de grupos alimentares que possuem vitaminas e sais minerais em sua composição, como verduras, legumes e frutas, e a relação com a fragilidade nos idosos. Não houve associação significativa que o consumo desses alimentos pode agir como 
fator protetor da síndrome. A ingestão de frutas, mesmo que não significativo, apresentou um consumo mais elevado pelos grupos de idosos pré-frágeis e não frágeis comparados ao grupo dos fragilizados.

Em relação à análise de contingência referente ao teste de chances, com exceção das vitaminas $A$ e $C$, que já foram citadas anteriormente, a maioria dos outros nutrientes apresentaram OR muito próximos a um, ou seja, do valor de igualdade. Os nutrientes que mais chamaram a atenção, mesmo que sem diferença significativa, foram a vitamina B2 e o ferro, com OR de 2, e o ácido graxo ômega 6, com OR de 3. A hipótese mais provável para estes diferenciais é a maior ingestão pelos idosos pré frágeis de energia e carboidratos, pois muitas vezes essa maior ingestão de carboidratos provém de alimentos também fontes de óleos vegetais em sua preparação, como em alimentos empanados e fritos, bolos, tortas etc. O óleo de soja, referido no ato da coleta como principal óleo utilizado nos domicílios, apresenta boa fonte de vitamina B2 e ácido graxo ômega 6 . Isso, na verdade, eleva a ingestão desse nutriente, porém de uma maneira negativa e acaba por ser um fator gerador de confusão em análises de dietas, quando o objetivo é analisar a adequação com base na ingestão total de nutrientes e sem levar em consideração a qualidade global da dieta. Sobre a ingestão de ferro, ambos os grupos mostraram adequações superiores a $150 \%$ de ingestão referente às DRI's. Desta maneira, acredita-se que o teste de chances só reflita a ingestão elevada do nutriente e não seu potencial de risco ou proteção. 


\section{Capítulo 5}

\section{Conclusão}

O presente trabalho nos permite concluir que os idosos frágeis apresentam idade mais avançada, principalmente na faixa etária de 80 anos ou mais, e que em estudos da atenção primária à saúde, a participaçãogeral é maior de mulheres, e as mesmas, quando ultrapassam a margem dos 80 anos, se tornam mais suscetíveis à fragilidade em comparação aos homens, porém a maior prevalência de fragilidade ocorreu no sexo masculino.

Nos mostra também a coexistência do baixo peso e do excesso de peso entre os idosos frágeis, provável repercussão da Obesidade Sarcopênica, impulsionada pela transição epidemiológica e nutricional. A prevalência de Excesso de Peso (IMC $>27 \mathrm{~kg} / \mathrm{m}^{2}$ ) entre os idosos foi quase o mesmo valor de idosos Eutróficos, sendo que ao separar por grupos, o grupo de idosos frágeis tem ao mesmo tempo maior prevalência de Baixo Peso e Excesso de Peso, em comparação aos pré frágeis.

Ainda referente às DCNT, o trabalho mostra proporções semelhantes de diabetes, hipertensão arterial e dislipidemia entre os dois grupos de idosos, e prevalência significativamente maior de casos de osteoporose nos idosos frágeis. Mesmo que o modelo do estudo não nos permita entender a ordem da causalidade, estes dados mostram a importância da prevenção da osteoporose, pois independentemente da ordem de causalidade, é uma doença que está coexistindo com a fragilidade e de qualquer maneira causa danos ao seu portador, como provável até piora da fragilidade.

Conclui-se também, a necessidade urgente de pesquisas que visam traçar pontos de corte específicos para a população brasileira, em relação aos critérios de fragilidade e principalmente, à força de preensão manual. Além disso, desenvolver protocolos específicos para avaliação do critério de força para a fragilidade, com base nas queixas freqüentes dos idosos relacionadas a doenças reumáticas.

A relação da ingestão e adequação nutricional com a Síndrome da Fragilidade ainda é muito incerta e pouco explorada na literatura. Porém, sugere-se que a 
melhor hipótese deste trabalho, tange a tendência de idosos frágeis realizarem trocas não muito positivas em sua alimentação, ao abrir mão de alimentos muitas vezes mais consistentes e recorrendo a alimentos mais brandos, que muitas vezes são saudáveis, como no caso das frutas, mas que não possuem sozinhos, o poder de nutrir um organismo com demandas estruturais mais elevadas. Isso refletido pelos parâmetros alimentares encontrados, com e sem diferenças significativas, mas com valor clínico considerável. Outro ponto, é que independente da comparação da ingestão entre os grupos, dos 20 nutrientes avaliados, somente oito (40\%) mostram ingestão igual ou superior às DRl's, o que remonta a importância do monitoramento nutricional em idosos frágeis e também em risco de fragilização.

A amostra deste trabalho foi pequena, no entanto muitos outros trabalhos, com amostras parecidas ou bem maiores, também não conseguiram demonstrar muitas associações relevantes entre melhor alimentação e adequação nutricional com a prevenção e incidência ou progressão da fragilidade. O que falta neste caso, não são somente estudos com amostras maiores, mas sim, modelos epidemiológicos longitudinais prospectivos, somados a bons protocolos de pesquisa e profissionais capacitados para avaliar de maneira adequada o padrão alimentar dos idosos da comunidade. 


\section{Referências Bibliográficas}

AMARAL, Fabienne Louise Juvêncio dos Santos et al. Apoio social e síndrome da fragilidade em idosos residentes na comunidade. Ciência \& Saúde Coletiva, v. 18, p. 18351846, 2013.

AUGUSTI, Ana Carolina Veloso; FALSARELLA, Gláucia Regina; COIMBRA, Arlete Maria Valente. Análise da síndrome da fragilidade em idosos na atenção primária-Estudo transversal. Revista Brasileira de Medicina de Família e Comunidade, v. 12, n. 39, p. 1-9, 2017.

BARTALI, Benedetta et al. Low nutrient intake is an essential component of frailty in older persons. The Journals of Gerontology Series A: Biological Sciences and Medical Sciences, v. 61, n. 6, p. 589-593, 2006.

BATISTONI, Samila Sathler Tavares et al. Validade e confiabilidade da versão Brasileira da Center for Epidemiological Scale-Depression (CES-D) em idosos Brasileiros. Psico-USF (Impresso), 2010.

BEASLEY, Jeannette M. et al. Protein intake and incident frailty in the Women's Health Initiative observational study. Journal of the American Geriatrics Society, v. 58, n. 6, p. 1063-1071, 2010.

BENEDETTI, Tania B.; MAZO, Giovana Z.; DE BARROS, Mauro VG. Aplicação do questionário internacional de atividades físicas para avaliação do nível de atividades física de mulheres idosas: Validade concorrente e reprodutibilidade teste-reteste. Revista Brasileira de ciência e movimento, v. 12, n. 1, p. 25-34, 2008.

BENEDETTI, Tânia R. Bertoldo et al. Reprodutibilidade e validade do Questionário Internacional de Atividade Física (IPAQ) em homens idosos. Rev Bras Med Esporte, v. 13, n. 1, p. 11-6, 2007.

BOLLWEIN, Julia et al. Distribution but not amount of protein intake is associated with frailty: a cross-sectional investigation in the region of Nürnberg. Nutrition journal, v. 12, n. 1, p. 109, 2013.

BRASIL. MINISTÉRIO DA SAÚDE. SECRETARIA DE ATENÇÃO À SAÚDE. DEPARTAMENTO DE ATENÇÃO BÁSICA. Envelhecimento da Pessoa Idosa/Ministério da Saúde, Secretaria de Atenção à Saúde, Departamento de Atenção Básica. Brasília: Ministério da Saúde, 2006.

BRASIL. Portaria no 2.436, de 21 de setembro de 2017. Aprova a Política Nacional de Atenção Básica, estabelecendo a revisão de diretrizes para a organização da Atenção Básica, no âmbito do Sistema Único de Saúde (SUS). 2017.

CARVALHO FILHO, Eurico Thomaz de. Fisiologia do envelhecimento. In: Gerontologia: a velhice e o envelhecimento em visão globalizada. 2002. p. 60-70.

DA SILVEIRA BARROSO ALVES, Davi et al. Caracterização do envelhecimento populacional no município do Rio de Janeiro: contribuições para políticas públicas sustentáveis. Cadernos Saúde Coletiva, v. 24, n. 1, 2016. 
DO CENSO DEMOGRÁFICO, IBGE Sinopse. Rio de Janeiro, 2011. www. ibge. gov. br/.../estatistica/.../censo2010/.. acesso em, v. 20, n. 04, p. 2014, 2010.

DUARTE, Y. A. O.; LEBRÃO, M. L. Fragilidade e envelhecimento. In. Viana, E. et al.; Tratado de Geriatria e Gerontologia. Guanabara-Koogan, Rio de Janeiro, 3ª ed. rev. e ampl., 2011.

ELIOPOULOS, Charlotte. Enfermagem Gerontológica-7. Artmed Editora, 2010.

FRIED, Linda P. et al. Frailty in older adults: evidence for a phenotype. The Journals of Gerontology Series A: Biological Sciences and Medical Sciences, v. 56, n. 3, p. M146M157, 2001.

GORDILHO, Adriano et al. Desafios a serem enfrentados no terceiro milênio pelo setor saúde na atençäo integral ao idoso. In: Desafios a serem enfrentados no terceiro milênio pelo setor saúde na atençäo integral ao idoso. 2000.

HAIDAR, S. G. et al. Average versus maximum grip strength: which is more consistent?. Journal of Hand Surgery, v. 29, n. 1, p. 82-84, 2004.

INSTITUTO BRASILEIRO DE GEOGRAFIA E ESTATÍSTICA. MINISTÉRIO DO PLANEJAMENTO. Pesquisa Nacional de Saúde: Manual de Antropometria. Rio de Janeiro, 2013.

KARVETTI, R. L.; KNUTS, Lars Ruñar. Validity of the 24-hour dietary recall. Journal of the American Dietetic Association, v. 85, n. 11, p. 1437-1442, 1985.

KOBAYASHI, S. et al. Three-generation Study of Women on Diets and Health Study Group. High protein intake is associated with low prevalence of frailty among old Japanese women: a multicenter cross-sectional study. Nutr J, v. 12, p. 164, 2013.

LOURENÇO, Roberto Alves et al. Consenso brasileiro de fragilidade em idosos: conceitos, epidemiologia e instrumentos de avaliação. Geriatrics, Gerontology and Aging, v. 12, n. 2, p. 121-135, 2018.

LWANGA, Stephen Kaggwa et al. Sample size determination in health studies: a practical manual. 1991.

MALTA, Deborah Carvalho; MORAIS NETO, Otaliba Libânio de; SILVA JUNIOR, Jarbas Barbosa da. Apresentação do plano de ações estratégicas para o enfrentamento das doenças crônicas não transmissíveis no Brasil, 2011 a 2022. Epidemiologia e Serviços de Saúde, v. 20, n. 4, p. 425-438, 2011.

MAZO, Giovana Zarpellon; LOPES, Marize Amorim; BENEDETTI, Tânia Rosane Bertoldo. Atividade física e o idoso: concepção gerontológica. Sulina, 3ª ed., 2009.

MELLO, A. C. Aplicabilidade de parâmetros antropométricos e de bioimpedância elétrica na avaliação do estado nutricional de idosos [Dissertação de Mestrado]. Viçosa: Universidade Federal de Viçosa, 2009.

MELLO, Amanda de Carvalho et al. Consumo alimentar e antropometria relacionados à síndrome de fragilidade em idosos residentes em comunidade de baixa renda de um grande centro urbano. Cadernos de Saúde Pública, v. 33, p. e00188815, 2017. 
MELLO, Amanda de Carvalho. Aspectos nutricionais, sociodemográficos e de saúderelacionados à síndrome de fragilidade em idosos moradores de Manguinhos, RJ. 2014. Tese de Doutorado.

MICHELON, Elisabete et al. Vitamin and carotenoid status in older women: associations with the frailty syndrome. The Journals of Gerontology Series A: Biological Sciences and Medical Sciences, v. 61, n. 6, p. 600-607, 2006.

MINISTÉRIO DA SAÚDE (BR). SECRETARIA DE ATENÇÃO À SAÚDE. DEPARTAMENTO DE ATENÇÃO BÁSICA. Orientações para a coleta e análise de dados antropométricos em serviços de saúde: Norma Técnica do Sistema de Vigilância Alimentar e NutricionalSISVAN. 2011.

MORLEY, John E. et al. Frailty consensus: a call to action. Journal of the American Medical Directors Association, v. 14, n. 6, p. 392-397, 2013.

NETO, Luiz S. Silva et al. Associação entre sarcopenia, obesidade sarcopênica e força muscular com variáveis relacionadas de qualidade de vida em idosas. Rev Bras Fisioter, v. 16, n. 5, p. 360-7, 2012.

NUTRITION SCREENING INITIATIVE et al. Incorporating nutrition screening and interventions into medical practice: a monograph for physicians. Washington DC: Nutrition Screening Initiative, 1994.

ORGANIZAÇÃO MUNDIAL DA SAÚDE. Relatório mundial de envelhecimento e saúde. 2015.

PADOVANI, Renata Maria et al. Dietary reference intakes: aplicabilidade das tabelas em estudos nutricionais. Revista de Nutrição, 2006.

PATE, Russell R. et al. Physical activity and public health: a recommendation from the Centers for Disease Control and Prevention and the American College of Sports Medicine. Jama, v. 273, n. 5, p. 402-407, 1995.

PEREIRA, Alexandre Alves; BORIM, Flávia Silva Arbex; NERI, Anita Liberalesso. Ausência de associação entre o índice de fragilidade e a sobrevivência de idosos no Brasil: Estudo FIBRA. Cadernos de Saúde Pública, v. 33, p. e00194115, 2017.

PEREIRA, Ingrid Freitas da Silva; SPYRIDES, Maria Helena Constantino; ANDRADE, Lára de Melo Barbosa. Estado nutricional de idosos no Brasil: uma abordagem multinível. Cadernos de Saúde Pública, v. 32, p. e00178814, 2016.

PINHEIRO, Ana Beatriz Vieira et al. Tabela para avaliação de consumo alimentar em medidas caseiras. In: Tabela para avaliação de consumo alimentar em medidas caseiras. 2008.

PROGRAMA DE APOIO A NUTRIÇÃO - NutWin [software]. Departamento de Informática em Saúde. Universidade Federal de São Paulo; 2005.

SEMBA, Richard D. et al. Low serum micronutrient concentrations predict frailty among older women living in the community. The Journals of Gerontology Series A: Biological Sciences and Medical Sciences, v. 61, n. 6, p. 594-599, 2006. 
SHIKANY, James M. et al. Macronutrients, diet quality, and frailty in older men. Journals of Gerontology Series A: Biomedical Sciences and Medical Sciences, v. 69, n. 6, p. 695701, 2013.

SMIT, Ellen et al. Lower nutritional status and higher food insufficiency in frail older US adults. British Journal of Nutrition, v. 110, n. 1, p. 172-178, 2013.

TACO, NEPA. Tabela brasileira de composição de alimentos. Revista Ampliada NEPA UNICAMP, p. 161, 2011.

TEIXEIRA, Ilka Niceia D. et al. Definições de fragilidade em idosos: uma abordagem multiprofissional. 2006.

TEIXEIRA, Ilka Nicéia D.'Aquino Oliveira. Revisão da literatura sobre conceitos e definições de fragilidade em idosos. Revista Brasileira em Promoção da Saúde, v. 21, n. 4, p. $297-$ 305, 2012.

VERAS, Renato. A novidade da agenda social contemporânea: a inclusão do cidadão de mais idade. A Terceira idade, v. 14, n. 28, p. 6-29, 2003.

WORLD HEALTH ORGANIZATION et al. Envelhecimento ativo: uma política de saúde. 2005.

WORLD HEALTH ORGANIZATION et al. Active ageing: A policy framework. Geneva: World Health Organization, 2002.

ZAINUDDIN, NurZetty Sofia et al. Association between Nutritional Status, Food Insecurity and Frailty among Elderly with Low Income. Jurnal Sains Kesihatan Malaysia (Malaysian Journal of Health Sciences), v. 15, n. 1, 2017. 


\section{APÊNDICE 1.}

\section{TERMO DE CONSENTIMENTO LIVRE E ESCLARECIDO}

(Resolução 466/2012 do Conselho Nacional de Saúde)

\section{"INGESTÃO DE NUTRIENTES E SUA RELAÇÃO COM A SÍNDROME DA FRAGILIDADE EM IDOSOS DE UMA UNIDADE DE SAÚDE DA FAMÍLIA DE RIBEIRÃO PRETO, SÃO PAULO."}

Eu, Nutricionista Fernando Barbosa Peixoto, pesquisador responsável pela presente pesquisa e Residente Multiprofissional da Faculdade de Medicina de Ribeirão Preto da Universidade de São Paulo, sob a orientação do Prof. Dr. Amaury Lelis Dal Fabbro, do Departamento de Medicina Social da Faculdade de Medicina de Ribeirão Preto da Universidade de São Paulo, convidamos o Sr (a) a participar como voluntário do projeto de pesquisa intitulado "INGESTÃO DE NUTRIENTES E SUA RELAÇÃO COM A SÍNDROME DA FRAGILIDADE EM IDOSOS DE UMA UNIDADE DE SAÚDE DA FAMÍLIA DE RIBEIRÃO PRETO, SÃO PAULO.", que tem por objetivo avaliar a ingestão de nutrientes envolvidos na saúde óssea e muscular e a sua relação com a Síndrome da Fragilidade em idosos cadastrados em uma unidade de Estratégia de Saúde da Família no município de Ribeirão Preto, São Paulo.

Caso o $\mathrm{Sr}$ (a) concorde com o convite, o Nutricionista irá agendar 2 (duas) visitas domiciliares. Na primeira visita o $\mathrm{Sr}$ (a) responderá a 1 (um) questionário composto por perguntas relacionadas a perda de peso, atividade física, fadiga e consumo alimentar, com duração estimada de aproximadamente 50 minutos. Na segunda visita irá responder a 1 (um) questionários de consumo alimentar e realizar 2 (dois) testes práticos, 1 (um) para avaliação da marcha e 1 (um) para avaliação da força muscular, tudo com duração estimada de aproximadamente de 40 minutos. Para o teste da força muscular através da preensão palmar, será solicitado para apertar com a mão o equipamento denominado dinamômetro e repetir o procedimento mais 2 (duas) vezes. Para a avaliação da marcha em segundos será solicitado para que o $\mathrm{Sr}$ (a) caminhe em velocidade confortável por uma distância de $4.6 \mathrm{~m}$, uma única vez.

A participação no projeto através dos questionários e testes práticos não irá interferir ou prejudicar nenhum acompanhamento ou tratamento de saúde que o $\mathrm{Sr}$ (a) esteja realizando atualmente ou venha a realizar no futuro. Em alguns casos serão coletadas informações, como dados cadastrais; informações de contato e peso prévio, através do prontuário de saúde do usuário.

As visitas domiciliares serão agendadas conforme sua a disponibilidade.

Os procedimentos envolvidos nesta pesquisa poderão causar algum desconfortodecorrente dos testes físicos, pelo tempo demandado para responder aos questionários e pela exposição dos hábitos alimentares.

Caso o $\mathrm{Sr}$ (a) se sinta incomodado ou cansado, poderá pedir para que sejam encerradas as avaliações a qualquer momento. 
Se o $\mathrm{Sr}$ (a) participar da pesquisa, terá como benefício direto as orientações nutricionais para melhora da qualidade de vida e o encaminhamento necessário nos casos de identificação da Síndrome da Fragilidade, caso esteja sem acompanhamento clínico.

Como a sua participação é voluntária, você tem o direito de se recusar a participar, bem como interrompê-la a qualquer momento, sem que haja qualquer tipo de punição ou penalização.

Antes e durante toda a pesquisa, o senhor (a) tem o direito de ser esclarecido sobre todos os procedimentos.

Os responsáveis por essa pesquisa se comprometem a prestar assistência integral no decorrer da pesquisa, se algum problema decorrer desta. Se verificado alguma alteração os mesmos receberão orientações e serão encaminhados, se necessário, para o Núcleo de Saúde da Família 3, localizado na Travessa Nossa Senhora da Penha, no 55, bairro Sumarezinho.

A participação na pesquisa não implicará em nenhum custo ou prejuízo financeiro.

Os materiais e as informações obtidos no desenvolvimento deste trabalho serão utilizados apenas para atingir os objetivos previstos nesta pesquisa, portanto, não serão utilizados para outras pesquisas sem o devido consentimento dos voluntários. Os dados serão analisados de forma global, exclusivamente para este estudo e não haverá a identificação individual dos participantes, garantindo o sigilo e de seus dados e de sua participação na pesquisa.

Os materiais e os dados obtidos ao final da pesquisa serão arquivados em CD sob a responsabilidade dos pesquisadores supracitados.

Os resultados da pesquisa serão tornados públicos por meio de apresentação em encontros científicos e publicação em periódico científico, respeitando-se sempre a privacidade e os direitos individuais dos sujeitos da pesquisa.

Concordando com sua participação voluntaria na pesquisa, você assinará este Termo de Consentimento Livre e Esclarecido e receberá uma via deste termo devidamente assinada, a qual consta os dados e assinatura dos pesquisadores responsáveis, caso necessite de maiores informações, ou por qualquer outra necessidade.

Caso você tenha alguma dúvida e/ou reclamação quanto à pesquisa ou a seu desenvolvimento, além de poder perguntar aos responsáveis pela pesquisa, também poderá entrar em contato com o Comitê de Ética em Pesquisa do Centro de Saúde Escola - CSE/Cuiabá da Faculdade de Medicina de Ribeirão Preto da Universidade de São Paulo - FMRP/USP, pelo telefone (16) 3315-0000.

$\mathrm{Eu}$, $R G$

assino este Termo de Consentimento com a finalidade de aceitar o convite $e$ participar como sujeito da pesquisa intitulada "INGESTÃO DE NUTRIENTES E SUA RELAÇÃO COM A SÍNDROME DA FRAGILIDADE EM IDOSOS DE UMA UNIDADE DE SAÚDE DA FAMÍLIA DE RIBEIRÃO PRETO, SÃO PAULO.”, de 
responsabilidade do Nutricionista Fernando Barbosa Peixoto, Residente da Faculdade de Medicina de Ribeirão Preto da Universidade de São Paulo, sob orientação do Prof. Dr. Amaury Lelis Dal Fabbro, docente no Departamento de Medicina Social da Faculdade de Medicina de Ribeirão Preto da Universidade de São Paulo, e afirmo que foram dadas todas as explicações necessárias, contidas acima, para eu tomar essa decisão de livre e espontânea vontade. Aceitei participar do projeto e recebi uma via desse Termo de Consentimento Livre e Esclarecido assinada por todos os pesquisadores.

Ribeirão Preto de de

Participante ou representante legal

Fernando Barbosa Peixoto

Mestrando em Saúde Pública - FMRP/USP

Prof. Dr. Amaury Lelis Dal Fabbro

Orientador - Departamento de Medicina Social-FMRP-USP

Fernando Barbosa Peixoto - Núcleo de Saúde da Família 3 - Travessa Nossa Senhora da Penha, oㅡ55, bairro Sumarezinho - Telefone: (16) 3633-3242 e-mail: fernandopeixotonutricao@gmail.com.

Prof. Dr. Amaury Lelis Dal Fabbro, do Departamento de Medicina Social da Faculdade de Medicina de Ribeirão Preto da Universidade de São Paulo. TEL (16) 3602-2714 e-mail: adfabbro@fmrp.usp.br. 
APÊNDICE 2.

FICHA DE AVALIAÇÃO PARA PESQUISA

Data:

\section{1 - DADOS DE IDENTIFICAÇÃO}

1. Número de Prontuário:

2. Número de Família:

3. Nome Completo:

4. Data de nascimento:

5. Profissão:

6. Sexo: ( ) Masculino ( ) Feminino

7. Endereço:

8. Telefones de contato:

9. Possui cuidador? ( ) Sim ( ) Não

9a. Nome do cuidador:

9b. Telefone cuidador:

2 - ATIVIDADE FÍSICA (IPAQ - Questionário Internacional de Atividade Física anexo 2.)

\section{3 - AVALIAÇÃO DO PESO E DA FRAGILIDADE}

1. PERDA DE PESO:

O Sr.(a) perdeu $4,5 \mathrm{~kg}$ ou mais no último ano? (isto é, sem dieta ou exercício físico)? ( ) Sim ( ) Não 


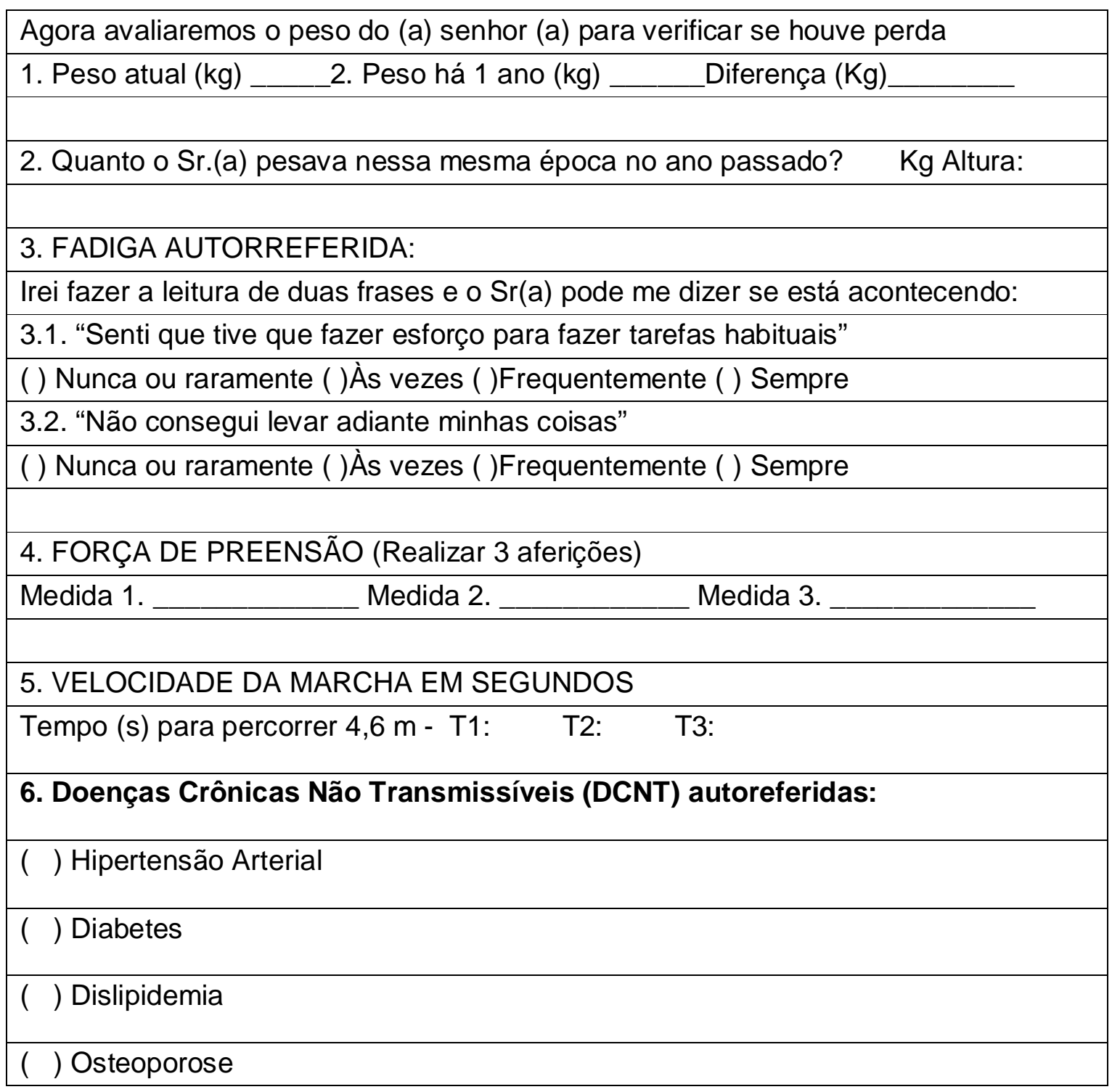




\section{ANEXO 1.}

THE CES-D SCALE: A SELF-REPORT DEPRESSION SCALE FOR RESEARCH IN THE GENERAL POPULATION

Table 1. CES-D Scale

INSTRUCTIONS FOK QUESIIONS: Below is a list of the ways you might have felt or behived. Please tell me how often you have felt this way during the pasc week. HAND CARD A. Rarely or None of the Time (Less than 1 Day)

Some or a Little of the Time (1-2 Days)

Occasionally or a Moderate Amount of Time (3-4 Days) Most or All of the Time (5-7 Days)

During the past week:

1. I was bothered by things that usually don't bother me.

2. I did not feel like eating; my appetite was poor.

3. I felt that I could not shake off the blues even with help from my family or friends.

4. I felt that I was just as good as other people.

5. I had trouble keeping my mind on what I was doing.

6. I felt depressed.

7. I felt that everything I did was an effort.

8. I felt hopeful about the future.

9. I thought my life had been a failure.

10. I felt fearful.

11. My sleep was restless.

12. I was happy.

13. I talked less than usual.

14. I felt lonely.

15. People were unfriendly.

16. I enjoyed life.

17. I had crying spells.

18. I felt sad.

19. I felt that people dislike me.

20. I could not get "going." 
ANEXO 2.

\section{QUESTIONÁRIO INTERNACIONAL DE ATIVIDADE FÍSICA Versão 8 (forma longa, semana usual)}

Nome:__ Data:______ Idade: ___anos

Nesta entrevista estou interessado em saber que tipo de atividades físicas o(a) senhor(a) faz em uma semana normal (típica). Suas respostas ajudarão a entender quanto ativos são as pessoas de sua idade.

As perguntas que irei fazer estão relacionadas ao tempo que você gasta fazendo atividades físicas no trabalho, em casa (no lar), nos deslocamentos à pé ou de bicicleta e no seu tempo de lazer (esportes, exercícios, etc.).

Portanto, considere como atividades físicas todo movimento corporal que envolve algum esforço físico. Lembre que as atividades VIGOROSAS são aquelas que precisam de um grande esforço físico e que fazem o(a) senhor(a) respirar MUITO mais forte que o normal. As atividades físicas MODERADAS são aquelas que exigem algum esforço físico e que fazem o(a) senhor(a) respirar um pouco mais forte que o normal.

\section{SEÇÃO 1 - ATIVIDADE FísICA NO TRABALHO}

Esta seção inclui as atividades que você faz no seu trabalho, seja ele remunerado ou voluntário. Inclua as atividades que você faz na universidade, faculdade ou escola. Você não deve incluir as tarefas domésticas, cuidar do jardim e da casa ou tomar conta da sua família. Estas serão incluídas na seção 3.

1 a. A tualmente você tem ocupação remunerada ou faz trabalho voluntário fora de sua casa?

$$
\bigcirc \mathrm{SIM} \quad \mathrm{NÃO} \rightarrow \text { Vá para seção } 2 \text { - Transporte }
$$

\begin{tabular}{|c|c|}
\hline $\begin{array}{l}\text { Orientações do } \\
\text { Entrevistador }\end{array}$ & $\begin{array}{l}\text { - As próximas questões são em relação ao tempo que você passa no } \\
\text { trabalho (fora de casa) seja ele remunerado ou voluntário. } \\
\text { - Por favor, NÃO INCLUA o transporte para o trabalho. } \\
\text { - Pense apenas naquelas atividades que durem pelo menos } 10 \text { minutos } \\
\text { Pontínuos }\end{array}$ \\
\hline
\end{tabular}

1b. Em quantos dias de uma semana normal você participa (realiza) atividades físicas vigorosas, de forma contínua por pelo menos 10 minutos (exemplo: trabalho de construção pesada, levantar e transportar objetos pesados, cortar lenha, serrar madeira, cortar grama, pintar casa, cavar valas ou buracos, etc.)?

\begin{tabular}{|c|c|c|c|c|c|c|c|c|}
\hline \multirow{3}{*}{ 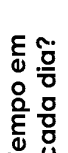 } & \multicolumn{2}{|c|}{ DIAS por semana } & \multicolumn{3}{|c|}{ Não faz AF vigorosas } & para o & stão lc & \\
\hline & DIA & Segunda & Terça & Quarta & Quinta & Sexta & Sábado & Domingo \\
\hline & Tempo & & & & & & & \\
\hline
\end{tabular}

1c. Em quantos dias de uma semana normal você participa (realiza) atividades físicas MODERADAS, de forma contínua por pelo menos 10 minutos (exemplo: levantar e transportar pequenos objetos, limpar vidros, varrer ou limpar o chão, carregar crianças no colo, lavar roupas com as mãos, etc.)?

\begin{tabular}{|c|c|c|c|c|c|c|c|c|}
\hline \multirow{3}{*}{ 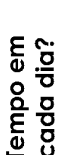 } & \multicolumn{2}{|c|}{ DIAS por semana } & \multicolumn{6}{|c|}{ Não faz AF moderadas $\rightarrow$ Vá para questão ld } \\
\hline & $\mathrm{DIA}$ & Segunda & Terça & Quarta & Quinta & Sexta & Sábado & Domingo \\
\hline & Tempo & & & & & & & \\
\hline
\end{tabular}


1d. Em quantos dias de uma semana normal você realiza caminhadas no seu rabalho, de forma cortínua por pelo menos 10 minutos?

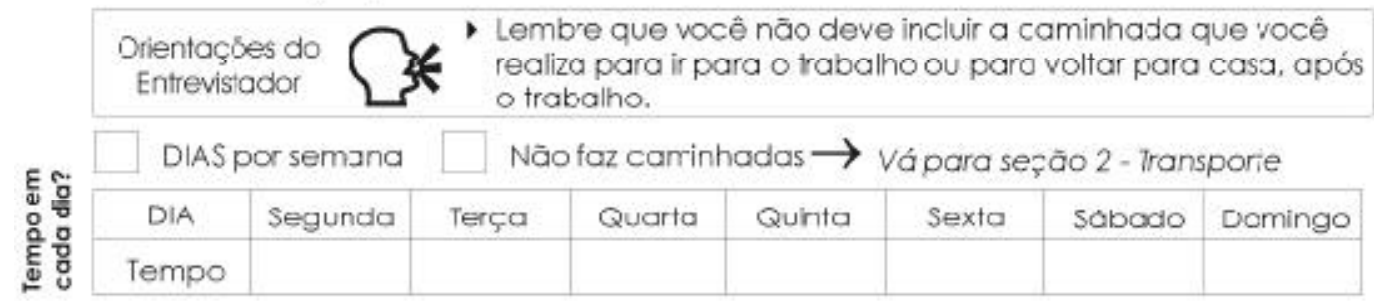

SEÇÃO 2 - AIIVIDADE FÍSICA COMO MEIO DE TRANSPORTE

As pergunias desta seção estão relacionadas d̀s atividades que você realiza para se deslocar de um lugar para outro. Vocs ceve incluir os desbcamentes para o trabalhs (se vocs trabalha). encontro do grupo de terceira idade, cinema supermercado, lojas ou qualquer outro local.

2a. Em quantos dias de uma semana normal você anda de carro, ônibus, metrô ou trem?

\begin{tabular}{|c|c|c|c|c|c|c|c|c|}
\hline \multirow{3}{*}{ 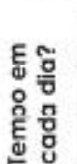 } & \multicolumn{2}{|c|}{ DIAS por serrana } & \multicolumn{3}{|c|}{ Não utiliza veículos a motor } & \multicolumn{3}{|c|}{$\rightarrow$ vápara a questāo $2 b$} \\
\hline & DIA & Segunda & Terça & Quarta & Quinta & Sexta & Sábodo & Domingo \\
\hline & Tempo & & & & & & & \\
\hline
\end{tabular}

crientaçás do 2 "Agora pense somente em relaçāc aos deslocamentos que você

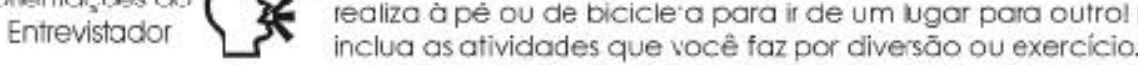

$2 \mathrm{~b}$. Em quantos dias de uma somana normal voces anda do biciclota, por polo monos 10 minutos contínuos, para ir de um lugar para outro, ?

\begin{tabular}{|c|c|c|c|c|c|c|c|}
\hline \multicolumn{2}{|c|}{ IAS por ser } & \multicolumn{3}{|c|}{ Näo anda de bicicleta } & Vópq & questāo & \\
\hline DIA & Segunda & Terça & Quarta & Qunta & Sexta & Sábcodo & Domingo \\
\hline Temp & & & & & & & \\
\hline
\end{tabular}

2c. Em quantos dias de uma semana normal você caminha por pelo menos 10 minutos cantínuos, para ir de um lugar para outro?

\begin{tabular}{|c|c|c|c|c|c|c|c|c|}
\hline \multirow{3}{*}{ 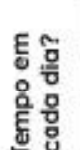 } & \multicolumn{2}{|c|}{ DIASpur sermanu } & \multicolumn{6}{|c|}{ Nüu fu< curnintíudus $\rightarrow$ vá para a Seçao 3} \\
\hline & DIA & Segunda & Terça & Quarta & Qunta & Sexta & Sábodo & Domingo \\
\hline & Tempo & & & & & & & \\
\hline
\end{tabular}

\section{SEÇĀO 3 - ATIVIDADE FÍSICA EM CASA, IAREFAS DOMÉSTICAS E ATENÇÃO À FAMÍLIA}

\footnotetext{
2. As perguntas desta seçũo estũo relacioncadas ùs atividades que o(a) senhor(a) realiza na sua casa e ao redor da s.ja casa. Nestas atividades estão incluidas as tarefas no jardim ou quintal, nanuterção da casa e cquelas que você faz para tomar conta do sua familia.
}

3a. tm quantos dias de uma semana normal voce taz atividades tísicos vigorosas no jardim ou quintal, por pelo menos 10 minutos contínuos? (Exemplo: carpir, cartar lenta, serrar, pintar, levantar e transpartar objetos pesados, ccrtar grama com tesoura etc.).

\begin{tabular}{|c|c|c|c|c|c|c|c|c|}
\hline \multirow{3}{*}{ 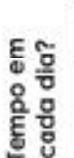 } & \multicolumn{3}{|c|}{ DIAS jor semana } & \multicolumn{5}{|c|}{ Ná taz At vigorosas em casa $\rightarrow$ vá fara questão $3 b$} \\
\hline & DIA & Segunda & Terça & Quara & Quinta & Sexta & Súbado & Domingo \\
\hline & Termpo & & & & & & & \\
\hline
\end{tabular}


